University of Louisville

ThinkIR: The University of Louisville's Institutional Repository

\title{
The beta- 2 adrenergic receptor polymorphisms and risk of breast cancer among hispanic and non-hispanic white women from the 4-corners breast cancer study : a population-based case-control examination.
}

Avonne Elish Connor

University of Louisville

Follow this and additional works at: https://ir.library.louisville.edu/etd

\section{Recommended Citation}

Connor, Avonne Elish, "The beta-2 adrenergic receptor polymorphisms and risk of breast cancer among hispanic and non-hispanic white women from the 4-corners breast cancer study : a population-based case-control examination." (2011). Electronic Theses and Dissertations. Paper 271.

https://doi.org/10.18297/etd/271

This Doctoral Dissertation is brought to you for free and open access by ThinkIR: The University of Louisville's Institutional Repository. It has been accepted for inclusion in Electronic Theses and Dissertations by an authorized administrator of ThinkIR: The University of Louisville's Institutional Repository. This title appears here courtesy of the author, who has retained all other copyrights. For more information, please contact thinkir@louisville.edu. 
THE BETA- 2 ADRENERGIC RECEPTOR POLYMORPHISMS AND RISK OF BREAST CANCER AMONG HISPANIC AND NON-HISPANIC WHITE WOMEN FROM THE 4-CORNERS BREAST CANCER STUDY - A POPULATION-BASED CASE-CONTROL EXAMINATION

\title{
By
}

Avonne Elish Connor

B.A., University of Louisville, 2005

MPH, University of Louisville, 2007

\author{
A Dissertation \\ Submitted to the Faculty of the \\ School of Public Health and Information Sciences \\ of the University of Louisville \\ in Partial Fulfillment of the Requirements \\ For the Degree of \\ Doctor of Philosophy \\ Department of Epidemiology and Population Health \\ University of Louisville \\ Louisville, KY
}

August 2011 
THE BETA- 2 ADRENERGIC RECEPTOR POLYMORPHISMS AND RISK OF BREAST CANCER AMONG HISPANIC AND NON-HISPANIC WHITE WOMEN FROM THE 4-CORNERS BREAST CANCER STUDY- A POPULATION-BASED CASE-CONTROL EXAMINATION

\author{
By \\ Avonne Elish Connor \\ B.A. University of Louisville, 2005 \\ MPH, University of Louisville, 2007
}

A Dissertation Approved on

July 21,2011

By the following Dissertation Committee:

Kathy B. Baumgartner, $\mathrm{PhD}$ (Committee Chair)

Richard Baumgartner, $\mathrm{PhD}$

Liz O’Brien, $\mathrm{PhD}$

Richard Kerber, PhD

Shesh Rai, $\overrightarrow{P h D}$ 


\section{ACKNOWLEDGMENTS}

Special thanks are extended to Dr. Kathy Baumgartner, my advisor, committee chair, and mentor. Your exemplary leadership, professionalism, and encouragement inspired me to achieve my educational objectives with confidence and perseverance. I would also like to thank my committee members Dr. Richard Baumgartner, Dr. Richard Kerber, Dr. Liz O'Brien, and Dr. Shesh Rai, for their time, efforts, and assistance throughout my doctoral program and dissertation. A special heartfelt thanks is given to Dr. Richard Kerber for his technical expertise and collaboration with this project. In addition, acknowledgements and thanks are offered to Dr. Marty Slattery, Dr. Roger Wolff, Dr. Tim Byers, and Dr. Anna Giuliano for their collegial support with the 4Corners Breast Cancer Study. I would also like to recognize Stephanie Denkhoff, Michael Hoffman, and Erica Wolff for their dedication and assistance with the completion of my lab component for this dissertation.

The research was funded by the following: CA 07862, CA 078762, CA078552, CA078802, and CA14002. This research was also supported by the Utah Cancer Registry, which is funded by Contract \#N01-PC-6700 from the National Cancer Institute, with additional support from the State of Utah Department of Health, the New Mexico Tumor Registry, and the Arizona and Colorado cancer registries, funded by the Centers for Disease Control and Prevention National Program of Cancer Registries and additional state support. This dissertation study was completed and also funded under the Susan G. 
Komen Breast Cancer Disparities Epidemiology Research Training Program: University of Louisville (Grant \#KG09092). 


\begin{abstract}
THE BETA - 2 ADRENERGIC RECEPTOR POLYMORPHISMS AND RISK OF BREAST CANCER AMONG HISPANIC AND NON-HISPANIC WHITE WOMEN FROM THE 4-CORNERS BREAST CANCER STUDY- A POPULATION-BASED CASE-CONTROL EXAMINATION
\end{abstract}

Avonne E. Connor

July 21,2011

Polymorphisms in the adrenergic receptor beta-2 (ADRB2) gene have been studied in relation to risk of Type 2 diabetes and obesity, but few studies have investigated associations with breast cancer. The purpose of this research was to evaluate the primary hypothesis that ADRB2 variants (rs1042713-Arg16Gly and rs1042714Gln27Glu) are associated with breast cancer risk in non-Hispanic white (NHW) and Hispanic $(\mathrm{H})$ women using data from a population-based case-control study conducted in the southwestern United States: 'The 4-Corners Breast Cancer Study'. A total of 1,244 NHW and $606 \mathrm{H}$ cases with incident primary breast cancer were ascertained and 1,330 NHW and $728 \mathrm{H}$ population-based controls were selected. Information on lifestyle and physical activity, diet, demographics, and reproductive background was collected through an in-person questionnaire, and blood samples were taken for genetic analyses from consenting participants. ADRB2 genotypes for rs 1042713 and rs 1042714 were determined using PCR. Each genotype as well as their haplotypes was evaluated in multivariable logistic regression models to estimate the associations with breast cancer 
risk, while adjusting for potential confounders, including study center, history of diabetes, body mass index, genetic admixture, and menopausal status.

ADRB2 genotype frequencies were significantly different between NHW and $\mathrm{H}$ women. Individually, the ADRB2 polymorphisms were not associated with breast cancer in either ethnic group. However, having 2 copies compared to one or zero copies of the ADRB2 G-G haplotype was associated significantly with increased risk of breast cancer among NHW women [odds ratio (OR), 1.95; 95\% confidence interval (95\% CI), 1.263.01] but reduced risk among Hispanic women [OR, 0.74; 95\% CI, 0.50-1.09], (p-for interaction $=0.004$ ). Risk was significantly decreased in Hispanic women with a history of Type 2 diabetes and 2 copies of the G-G haplotype [OR, 0.33; 95\% CI, 0.12-0.92] while the association was increased, but not statistically significant among NHW women, $[\mathrm{OR}, 4.91 ; 95 \% \mathrm{CI}, 0.52-46.60],(\mathrm{p}$-for interaction $=0.025)$. While the interaction between obesity (body mass index (BMI) $\geq 30 \mathrm{~kg} / \mathrm{m}^{2}$ ) and the $\mathrm{G}-\mathrm{G}$ haplotype was not significant $(p=0.200)$, the association in NHW obese women with 2 copies of the G-G haplotype was similarly increased [OR, 3.01; 95\% CI, 1.22-7.44], but decreased in Hispanics [OR, $0.42 ; 95 \% \mathrm{CI}, 0.20-0.56]$. These data suggest that ethnicity modifies the association between the ADRB2 G-G haplotype and breast cancer risk and history of Type 2 diabetes and obesity enhances the divergence of risk between Hispanic and NHW women. 


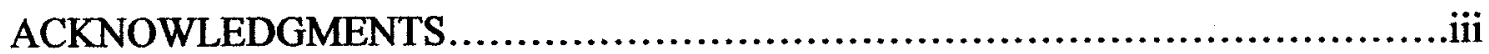

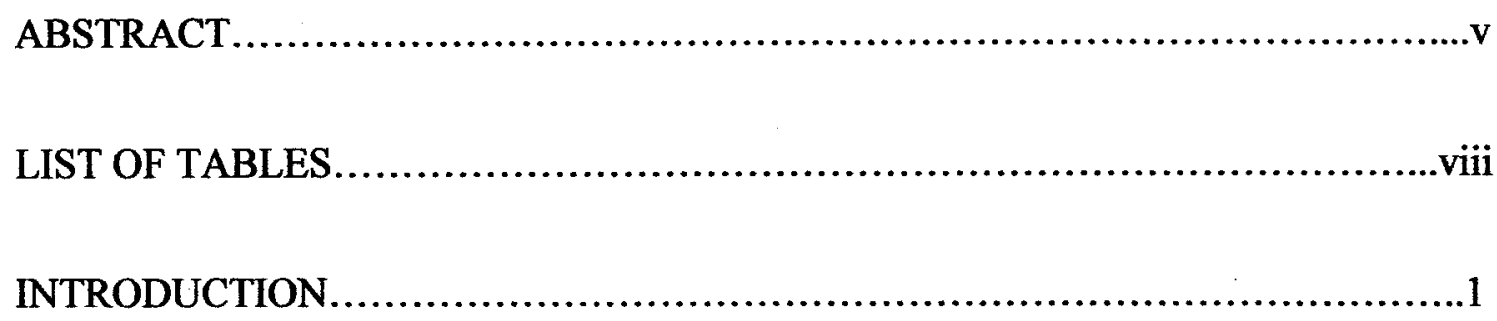

Specific Aims and Hypotheses................................................

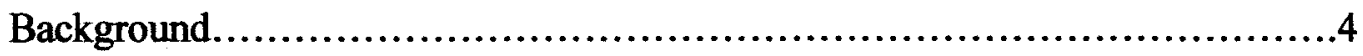

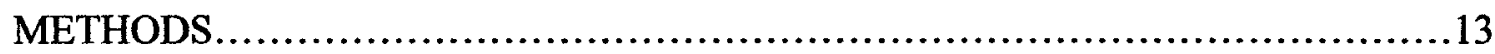

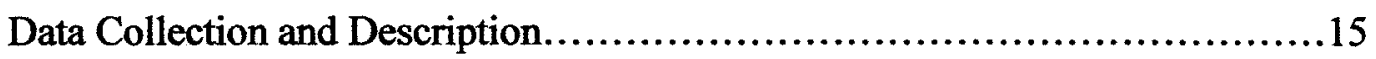

Methods of Data Analyses..................................................21

Sample Size and Statistical Power Calculation................................26

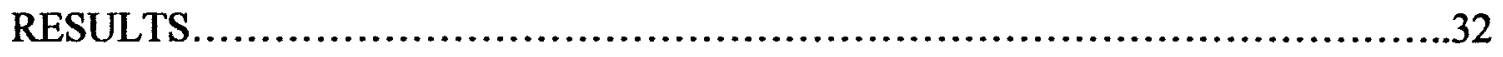

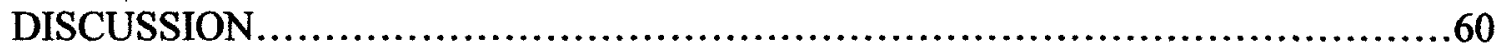

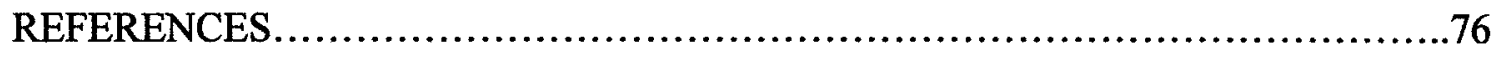

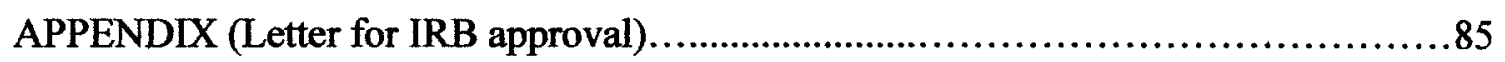

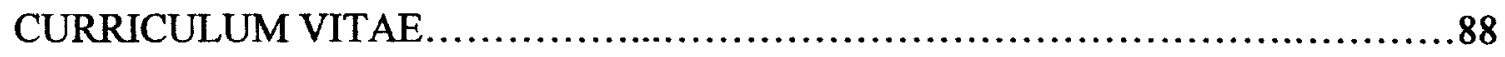




\section{LIST OF TABLES}

TABLE

PAGE

1. Table 1A. Proportion Values for Recessive Model " $0+1$ vs. 2 " ...................28

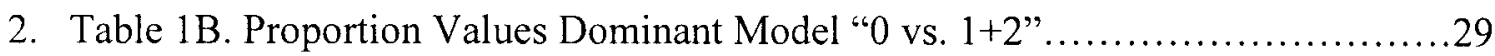

3. Table 2A. Power Analysis for 4-CBCS $(n=3,908)$ for Recessive

Model " $0+1$ vs. 2 " 30

4. Table 2B. Power Analysis for 4-CBCS $(n=3,908)$ for Dominant

Model " 0 vs. $1+2$ "

5. Table 3. Characteristics of Study Population, Stratified by Ethnicity and Case-Control Status, 4-Corners Breast Cancer Study, $1999-2002(n=3,908)$

6. Table 4. Test for Hardy Weinberg Equilibrium (HWE) by Ethnicity among Controls for ADRB2 SNPs from the 4-Corners Breast Cancer Study.... .36

7. Table 5. Genotype Characteristics of Study Population, Stratified by Ethnicity and Case-Control Status, 4-Corners Breast Cancer Study, 1999-2002

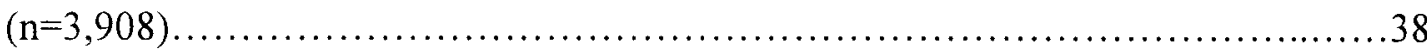

8. Table 6. Characteristics of the ADRB2 Polymorphisms...........................44

9. Table 7. Univariable Odds Ratios (OR) and 95\% Confidence Intervals for Demographic Characteristics from the 4-Corners Breast Cancer Study .44

10. Table 8. Univariable Odds Ratios (OR) and 95\% Confidence Intervals for Genetic Polymorphisms from the 4-Corners Breast Cancer Study. 
11. Table 9. Test of Interaction with Ethnicity using Model " $0+1$ vs. 2" G-G Haplotype for ADRB2

12. Table 10. Interaction between Ethnicity and G-G Haplotype of ADRB2 SNPs Using Model " $0+1$ vs. 2 "

13. Table 11. Test of Effect Modification by History of Diabetes with Ethnic-Specific ADRB2 G-G Haplotype

14. Table 12. Test of Effect Modification by Obesity with Ethnic-Specific

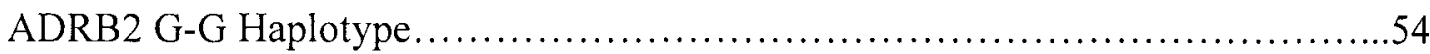

15. Table 13. Test of Effect Modification by Recent Hormone Exposure with Ethnic-Specific ADRB2 G-G Haplotype...................................55

16. Table 14. Statistical Interactions between ADRB2 G-G Haplotype by Ethnicity......56

17. Table 15. Distribution of Estrogen Receptor Status for Breast Cancer Cases from the 4-Corners Breast Cancer Study

18. Table 16. Multinomial Logistic Regression by Estrogen Receptor Status with EthnicSpecific ADRB2 G-G Haplotype. .58

19. Table 17. Association between Ethnic-Specific G-G Haplotype of ADRB2 SNPs with Diabetes. .59

20. Table 18. Association between Ethnic-Specific G-G Haplotype of ADRB2 SNPs with Obesity (BMI $\geq 30)$ .59 


\section{INTRODUCTION}

\section{Specific Aims, Hypotheses, and Background}

\section{Specific Aims and Hypothesis}

Polymorphisms in the adrenergic receptor beta-2 (ADRB2) gene have been studied in relation to risk of Type 2 diabetes and obesity, but few studies have investigated associations with breast cancer. It has been postulated that genetic traits related to obesity and obesity-related diseases could possibly influence the risk of breast cancer, given the known relationship between obesity and postmenopausal breast cancer. The purpose of this study is to evaluate the primary hypotheses that the following ADRB2 polymorphisms (rs1042713 (Arg16Gly) and rs1042714 (Gln27Glu) are associated with breast cancer risk in non-Hispanic white and Hispanic women using data from a population-based case-control study, 'The 4-Corners Breast Cancer Study'. The specific aims to conduct this proposed dissertation study and primary hypotheses are detailed below:

(1) To assay the following SNPs in the ADRB2 gene (rs1042714 (Gln27Glu), rs 1042713 (Arg 16Gly)) using stored DNA from the 4-Corners Breast Cancer Study.

(2) To determine the statistical associations of individual SNPs (rs 1042714 (Gln27Glu), rs1042713 (Arg16Gly)) and their haplotypes with breast cancer risk. 
(3) To determine the statistical interactions of the SNPs with theoretically defined effect modifiers including family history, ethnicity, obesity, menopausal status, estrogen receptor status, NSAID use, aspirin use, and functional SNPs in the following insulin/obesity related genes: IRS1, IRS2, IGF1, ADRB3, and IL6.

(4) To determine the statistical associations of individual SNPs (rs1042714 (Gln27Glu), rs1042713 (Arg16Gly)) and their haplotypes with obesity risk measured by body mass index and risk of Type 2 diabetes.

(5) To determine the statistical associations of individual SNPs (rs1042714 (Gln27Glu), rs 1042713 (Arg16Gly)) and their haplotypes with risk of breast cancer categorized by estrogen receptor status.

$\mathrm{H}_{1 \mathrm{~A}}$ : The risk of breast cancer for women who have the ADBR2 (rs1042714 (Gln27Glu), rs1042713 (Arg16Gly)) variant genotypes will be higher than for those who do not have the minor homozygous genotype, after adjustment for other relevant confounders.

$\mathrm{H}_{2 \mathrm{~A}}$ : The risk of breast cancer for women who have the ADRB2 haplotypes for the variants rs1042714 (Gln27Glu) and rs1042713 (Arg16Gly) will be higher than for those who do not have the minor disease causing haplotypes, after adjustment for other relevant confounders.

$H_{1 B}$ : The risk of breast cancer for women with the ADRB2 variant(s) will be modified by family history, ethnicity (non-Hispanic white vs. Hispanic ethnicity), markers for obesity (BMI) menopausal status, aspirin use, NSAID use, estrogen receptor status (ER+/ER-), IRS-1 (rs1801278) and IRS-2 (rs 1805097) variants, and other previously measured 
insulin/obesity related genes (IGF1, ADRB3) after controlling for other important covariates.

$\mathrm{H}_{2 \mathrm{~B}}$ : The proposed relationship between breast cancer for women with the ADRB2 variants and markers for obesity (BMI, waist circumference, waist/hip ratio) will demonstrate significant results for effect mediation.

$\mathrm{H}_{3 \mathrm{~B}}$ : The risk for obesity and Type 2 diabetes for women who have the rs 1042714 (Gln27Glu) and rs1042713 (Arg16Gly) variant alleles and genotypes will be higher than for those who do not have the minor homozygous genotype, after adjustment for other relevant confounders.

$\mathrm{H}_{4 \mathrm{~B}}$ : The risk for estrogen receptor negative tumors for women who have the rs 1042714 (Gln27Glu) and rs1042713 (Arg16Gly) variant genotypes will be higher than for those who do not have the minor homozygous genotype, after adjustment for other relevant confounders.

Important covariates to consider for the study analyses are: age, ethnicity, education, aspirin usage, NSAID usage, height, BMI at referent year, WHR categorized, waist circumference (centimeters), menstruation start age, menopausal status, age at first birth, parity, smoking status, physical activity, caloric intake, family history of breast cancer, diabetes history, IRS-1, IRS-2, IGF1, ADRB3, and IL6 variants (all of which are previously measured insulin/obesity related genes). 


\section{Background}

Adrenergic Receptor Beta 2 (ADRB2)

The beta-2-adrenergic receptor is a member of the G-protein-coupled adrenergic receptor family. It binds and is activated by catecholamines, more specifically epinephrine. The gene that codes for the beta-2-adrenergic receptor, the ADRB2 gene, is located on chromosome 5q31-q32 and consists of a single exon of 2015 nucleotides, encoding 413 amino acid proteins. ADRB2 has been found to regulate several systems through agonist-mediated vascular response, including the cardiac, pulmonary, vascular, endocrine, and central nervous systems [1].

There are over 80 polymorphisms for ADRB2, of which 45 SNPs have been identified. There are two non-synonymous SNPs that are more common which code for amino acid changes at positions 16 [arginine to glycine-Arg16Gly (rs1042713)] and 27 [glutamic acid to glutamine-Glu27Gln (rs1042714)] [1]. Previous literature has referred to the rs 1042714 polymorphism as Glu27Gln, however throughout this dissertation study report, the rs 1042714 is referred to as Gln27Glu [2]. The nucleotide changes for rs1042713 and rs1042714 are ExI $+265 \mathrm{G}>\mathrm{A}$ and Ex1+298G $>\mathrm{C}$, respectively. These common ADRB2 SNPs have been found to be associated with risk of Type 2 diabetes [35] and are suspected to play a role with risk of obesity in certain populations [6-8]; however, recent literature has documented mixed findings. Jalba et al. found the Glu27 allele to be associated with obesity in Asians, Pacific Islanders, and American Indians, but not among Europeans. They also concluded there was no association found between the Arg 16 allele and obesity [6]. It is known that the beta adrenergic receptors function in 
the adipose tissue by stimulating lipolysis, which in part could affect the regulation of energy expenditure and lipid mobilization within human fat cells [9].

Biological studies have indicated a carcinogenic role with the beta-2 adrenergic receptors in breast cancer cell lines through the over-expression of the arachidonic acidmetabolizing enzymes cyclooxygenase-2 and lypoxygenases [10]. Arachidonic acid (AA) metabolism can produce mutagens that can damage DNA and cause mutations. It has also been found that modulation of pathways for the AA metabolizing enzymes cyclooxygenase-2 and lypoxygenases can result in suppression of tumor growth [11]. Biological evidence of this mechanism for carcinogenesis has been found for adenocarcinomas of the lungs, pancreas and colon, all of which have demonstrated over expression of the arachidonic-metabolizing enzymes, presumably under beta-adrenergic control $[10,12]$. Plummer et al. hypothesized that the beta-adrenergic regulation of the arachidonic acid-mediated signaling occurs in breast adenocarcinomas by way of Gprotein coupled inwardly rectifying potassium channels (GIRKI). The expression of mRNA encoded with GIRKI has been found in roughly $40 \%$ of primary human breast cancer tissue samples [12].

Vandewalle et al. previously confirmed that the beta adrenergic compounds stimulated cAMP production in breast cancer cells. The production of cAMP has been implicated with tumor growth mechanisms and in lactose production [13]. Researchers have also speculated that specific beta-adrenergic receptors coupled with $G$ protein could play a role with circulating catecholamines which could function in the growth and differentiation of the mammary glands [14]. The pathophysiological significance of the 
beta-adrenergic receptors remains uncertain and more biological research is needed to explain their physiological role with the development of breast cancer.

Few epidemiological studies have examined the possible relationship of ADRB2 with breast cancer risk, based upon the relationship between obesity and postmenopausal breast cancer [15-16]. The assumption proposed by these investigators is that an indirect relationship may exist between genetic traits linked to obesity and risk of postmenopausal breast cancer. Huang et al. utilized a small sample of 200 breast cancer cases and 182 controls from Japan to investigate this association, and oddly found a non-statistically significant inverse association between rs 1042714 Glu vs. Gln/Gln and breast cancer risk; $\mathrm{OR}=0.67,95 \% \mathrm{CI}:(0.38-1.18)[15]$. In a nested case-control study among postmenopausal women from the American Cancer Society Cancer Prevention Study II Nutrition Cohort, Feigelson et al. [16] also investigated the relationship between ADRB2 in addition to other obesity related genes and breast cancer risk among 648 cases and 659 controls. The majority of women who participated were non-Hispanic white, while African American women only made up $12 \%$ of the study sample. For this particular study, tagging SNPs for ADRB2 were utilized to test for the associations. From the tagging SNPs identified (rs87741, rs2400707, rs10472718, and rs17108817), no statistically significant associations were found for breast cancer risk after adjusting for ethnicity, birth date, blood draw date, adult weight change, breast cysts, family history of breast cancer, and postmenopausal hormone use [16]. 
Adrenergic Receptor Beta 3 (ADRB3)

Located on chromosome $8 \mathrm{p}$, the adrenergic receptor beta 3 (ADRB3) has also been found to function in lipolysis and thermogenesis. Although the ADRB3 gene codes for 396 amino acids, little is known about other functional roles of this gene. Human fat cells are the only human cells available for ADRB3 functional studies [17-18]. The ADRB3 polymorphism Trp64/Arg has been implicated with the development of obesity and Type 2 diabetes, but conflicting results have been found. According to Arner et al, at least 15 studies have found no association between the Try64/Arg polymorphism and obesity [18]. In a meta-analysis by Kurokawa et al., the ADRB3 polymorphism was associated with BMI among east Asians, but not for Europeans [19]. In a study of African American breast cancer cases from the Health, Eating, Activity and Lifestyle Study, researchers found an increased risk of obesity among women who were homozygous for the ADRB3 wild-type allele $(\mathrm{OR}=2.1,95 \% \mathrm{CI}: 1.1-4.2)$ [20]. In a population of Danish subjects, the variant Arg64 was not found to be associated with risk of obesity but was found to be positively associated with Type 2 diabetes and increased insulin resistance [21]. Dunajska and colleagues did not find an association between the Arg64 variant with risk of developing metabolic syndrome among postmenopausal women [22], but interestingly, a positive association was found among obese males [23].

The association of the ADRB3 polymorphism Trp64/Arg with risk of breast cancer has also been investigated through epidemiological studies. Huang et al. also investigated the association of the Arg64 variant with breast cancer risk, but found an inverse association among their small case-control study $(\mathrm{OR}=0.85 ; 95 \% \mathrm{CI}: 0.55-1.31)$ [15]. As previously mentioned, Feigelson et al. also examined the ADRB3 
polymorphism in relation to breast cancer risk, and did not find an association, as with the selected ADRB2 variants [16]. The ADRB3 Try64/Arg polymorphism has been genotyped and analyzed prior to this dissertation as part of the 4-Corners Breast Cancer Study. Due to similarities between the physiological functions of ADRB2 and ADRB3 genes, interaction effects between these polymorphisms and risk of breast cancer are of interest for this dissertation study.

Insulin Receptor Substrate 1 and 2 (IRS-I and IRS2)

Insulin receptor substrates (IRSs) are intracellular proteins that function as signaling adaptors in the metabolic and mitogenic processes associated with hormone, cytokine, and growth factor signaling [24]. Within the past few years, more evidence has been found that implicates a link between IRSs activity and human cancer. In a study of breast cancer patients, it was reported that high IRS-1 levels were associated with poor outcomes [25]. In a later molecular study, mice that overexpressed human IRS-1 or IRS-2 in mammary tissue demonstrated advanced mammary hyperplasia, tumorigenesis, and metastasis; phenotypes were also associated with activation of $\beta$-catenin [24]. These IRS proteins also bonded with $\beta$-catenin in vitro and in vivo [24]. Interestingly in recent molecular cancer research, Bommer et al [26] demonstrated that the IRS-1 gene expression can be directly activated by $\beta$-catenin through the $\beta$-catenin/TCF complex that binds with elements downstream of the IRS-1 transcriptional start site. This study also found that IRS1 is highly expressed in cancers that demonstrate $\beta$-catenin stabilization $[26]$. 
In epidemiological research, the role of the IRS genes have been investigated with their relationship with breast cancer based upon their connection with cancer and other conditions that are considered important contributing factors for cancer risk [27]. As with specific variants of the ADRB2 gene, the IRS1 polymorphism rs 1801278, also known as G972R has been associated with insulin resistance and Type 2 diabetes, and the $\mathrm{R}$ allele has been found to increase the risk of colon cancer [28]. The IRS2 gene has also been found to be associated with obesity [29-30]. Using data from the 4-Corners Breast Cancer Study, Slattery et al. [27] investigated the relationship between IRS1 (G972R) and IRS2 (G1057D) and breast cancer risk, among other genetic polymorphisms. Postmenopausal women who had the R allele of the G972R IRS1 polymorphism (rs1801278) and were not recently exposed to hormones were found to have an increased risk of breast cancer ( $\mathrm{OR}=2.70,95 \% \mathrm{CI}$ : 1.13-6.46) after controlling for age, center, parity, energy intake, physical activity, and genetic admixture, [27]. An important factor to consider from this study is that these associations differed by ethnicity, which illuminates the importance of considering different metabolic pathways that may influence breast cancer risk which may vary between ethnic groups, possibly due to the genetic variation between ethnicities.

In the recent population-based breast cancer study conducted by Feigelson et al. [16], the associations between breast cancer and several candidate obesity genes, including IRS1 and IRS2 variants, were examined. This primarily non-Hispanic white sample considered the following covariates as potential confounders: BMI, adult weight change, postmenopausal hormone use, family history of breast cancer, and history of breast cysts. Effect modification was also tested for between genotypes and BMI, 
postmenopausal hormone use, family history of breast cancer, and history of breast cysts. Results did not demonstrate an association between IRS1 SNPS and breast cancer; however, three of the SNPS for IRS2 did show a significant association with breast cancer risk (rs4773082, $\mathrm{P}=0.007, \mathrm{rs} 2289046, \mathrm{P}=0.016$, rs 754204, $\mathrm{P}=0.03$ ) [16]. Although these findings with the three IRS2 variants were significant, the authors noted that they were not able to genotype the IRS2 variant rs 1805097 due to assay failure.

The other genes and their functional SNPs proposed for interaction effects that have been previously genotyped in the parent study were selected for this proposed dissertation study based on their potential role in a pathway linking energy balance and obesity to breast cancer through estrogen, insulin, and insulin-like growth factors $[27,31$ 33].

Obesity, Ethnicity, and Breast Cancer

The link between the ADRB2 gene and obesity is unclear; however, examining interaction effects between obesity predictors, the ADRB2 variants, and breast cancer risk or investigating by subgroup analyses seems logical given that obesity has been found to be associated with breast cancer. It is important to consider that the association with body size and breast cancer differs for premenopausal and postmenopausal breast cancers. For postmenopausal breast cancer, larger body size is associated with an increased risk for disease; this finding is believed to be attributed to the conversion of precursor substrates to estrogen in adipose tissue [34]. Contrastingly, for premenopausal women, an inverse association has been found between risk for breast cancer and increased adiposity [34]. Premenopausal who are overweight or obese may have a 
reduced risk of breast cancer due to increased frequency of anovulatory cycles [35] or due to increased parity, which tends to be associated with increased weight [36].

Various anthropometric measurements are used to describe adiposity including body mass index $\left(\mathrm{BMI} \mathrm{m} / \mathrm{kg}^{2}\right)$, waist circumference, and waist-hip-ratio (WHR). The relationship between these measurements and breast cancer risk has been widely researched. Results have been mixed as to which is the most accurate anthropometric predictor for breast cancer risk. Meta-analyses have shown for every unit increase in BMI, there is approximately a $3 \%$ increase in risk of postmenopausal breast cancer [37]. In the EPIC cohort study, waist circumference was associated with breast cancer risk with a relative risk of $1.12,95 \% \mathrm{CI}$ : $(1.02-1.24)$ per $10 \mathrm{~cm}$ increase in waist circumference measure, and for hip circumference, a relative risk of $1.14,95 \% \mathrm{CI}$ : $(1.02-1.27)$ per $10 \mathrm{~cm}$ increase in hip circumference measure was also found to be significant [38].

Interestingly, Morimoto et al. [39] found with the Women's Health Initiative Observational study that anthropometric measurements (BMI, WHR, waist circumference, hip circumference) were not associated with breast cancer risk among women who had ever used HRT. But they did find that among non-HRT users, the relative risk for postmenopausal breast cancer was $2.52,95 \% \mathrm{CI}$ : (1.62-3.93) for women with BMI $>31.1$, compared to slimmer women with $\mathrm{BMI} \leq 22.6$. Waist circumference and hip circumference were both associated with postmenopausal breast cancer risk independently among non-HRT users; however, WHR was not associated with postmenopausal breast cancer for non-HRT users [39]. 
Few studies have investigated the association between obesity and breast cancer among Hispanic women. However, a study conducted by Wenten et al [40] investigated associations between obesity factors and breast cancer risk among Hispanic and nonHispanic white women in New Mexico. After stratifying by menopausal status, results for BMI for non-Hispanic white women were not statistically significant; however, results were consistent with previous literature. Premenopausal women having a $\mathrm{BMI} \geq 30$ compared to $\mathrm{BMI}<22$, had a reduced risk for breast cancer, $(\mathrm{OR}=0.71 ; 95 \% \mathrm{CI}$ : 0.19 2.63), while postmenopausal women with $\mathrm{BMI} \geq 30$ compared to $\mathrm{BMI}<22$, had an increased risk, $(\mathrm{OR}=2.77,95 \% \mathrm{CI}$ : 0.86-8.89). Contrastingly, Hispanic women did not demonstrate this divergence in results, suggesting their relationship between obesity and breast cancer may be independent of menopausal status. Hispanic women with a BMI $\geq$ 30 had an increased risk for breast cancer regardless of premenopausal (OR=1.64, $95 \% \mathrm{Cl}: 0.52-5.11)$ or postmenopausal $(\mathrm{OR}=1.32,95 \% \mathrm{CI}: 0.47-3.72)$ status [40]. It has been suggested that ethnic differences in these results for pre and postmenopausal breast cancer risk could be attributed to the high prevalence of insulin resistance and hyperinsulinemia among the Hispanic population [40]. Obese women who are premenopausal normally have decreased levels of estradiol and progesterone, which can lower breast cancer risk. However, increased insulin levels could counterbalance these lower hormone levels among premenopausal obese women. This counterbalance seems very probable among Hispanic women who are susceptible to obesity and insulin resistance [40]. 


\section{METHODS}

The data for the proposed study is drawn from the 'Four Corners Breast Cancer Study' (4-CBCS), a population-based case-control study of breast cancer in Hispanic and non-Hispanic white women between the ages of 25 and 79 living in the following areas of the Southwestern U.S.: Arizona, Colorado, New Mexico, and Utah. The purpose of the original study was to investigate the differences between breast cancer incidence rates and prevalence of exposures among Hispanic/American Indian women and non-Hispanic white women. A secondary objective of the study was to investigate the association of candidate SNPs with breast cancer risk. These SNPs were selected based on their hypothesized roles in energy balance and obesity and were postulated to influence breast cancer risk through estrogen and insulin-related pathways [32].

\section{Selection of Case Subjects}

Cases were ascertained through the state tumor registries. The state of Utah utilized an electronic rapid case ascertainment system, while the other states used normal registry methods. The Utah and New Mexico cancer registries are funded by the National Cancer Institute as Surveillance Epidemiology and End Results registries. Colorado and Arizona registries are part of the Center for Disease Control National Program of Cancer Registries. All primary incident cases diagnosed with in situ or invasive breast cancer (ICDO sites C50.0-C50.6 and C50.8-C50.9) between October 1999 and May 2004 and with histological confirmation were eligible. Registries provided information on cases ethnicity, as well as estrogen and progesterone receptor tumor status for approximately 
$70 \%$ of cases [41]. The Generally Useful Ethnic Search System (GUESS) program was also utilized to identify Hispanic women included in the study by surname search [42]. For Hispanic cases that were initially identified as Hispanic by either surname search or from cancer registry records, $82.3 \%$ self-reported their ethnicity to be Hispanic at time of interview. For Hispanic controls that were identified by surname search only, this percentage was lower with $73.2 \%$ reported [43]

\section{Selection of Control Subjects}

Controls that were selected were frequency matched on ethnicity and 5-year age distribution of the cases. Therefore, the control subjects were chosen to ensure that the frequency of the matching factors (i.e. ethnicity and age distribution) were the same as found in the case group. Controls from Arizona and Colorado were randomly selected from a commercial mailing list if under the age of 65 years. For the states of New Mexico and Utah, controls under the age of 65 were randomly selected from the New Mexico and Utah driver's license lists. In all of the states, those controls 65 years of age and older were randomly selected from the Center for Medicare Services lists.

All women initially selected for the study were screened for eligibility prior to study inclusion. During the screening process, subjects were asked to self-identify their ethnicity and race and if their self-reported ethnicity/race did not match that of the GUESS program, these subjects were determined to be ineligible for study enrollment. Approximately $12 \%$ of cases and $14 \%$ of controls were excluded for this reason [41]. All participants of the 4-CBCS study signed informed written consent prior to participation. A total of $68 \%$ of the women contacted actually completed the study. There were a total 
of 945 Hispanic and 1,671 non-Hispanic white eligible controls that were interviewed in the parent study. For cases, a total of 798 Hispanic and 1,527 non-Hispanic White women were included as eligible for analyses [41]. The median time from diagnosis to interview was 599 days for New Mexico; 671 days for Arizona, 267 days for Utah, and 540 days for Colorado [41].

\section{Data Collection and Description}

The Institutional Review Board for Human Subjects from each institution approved the 4-CBCS study. Interviewer-administered computerized questionnaires were used by certified and trained interviewers to collect diet and lifestyle data. The interviewer training requirements were as follows. After seven audio taped interviews were conducted by trained individuals, interviewers were considered certified interviewers. All interviews after the initial seven were audio taped for quality control procedures and were selected randomly for quality control review. After 10 interviews were conducted by each interviewer, one was evaluated, until the interviewer had conducted 50 interviews, then one in 20 interviews was reviewed, or one interview per month if the interviewer had less than 20 interviews per month were conducted for that particular interviewer. The audio tapes were reviewed for the following aspects: interviewer behavior, probing, keeping the subject on task, not providing personal opinions, interrupting the subject, the reading of questions, and the quality of the data collection [41].

For Spanish speaking subjects, the questionnaire was translated into Spanish by two individuals with an arbitrator. Although the majority of Hispanic women completed 
their questionnaire in English, the percentages of Hispanic participants that completed their questionnaire in Spanish were as follows: 10\% for New Mexico site, $32 \%$ for Arizona, $10 \%$ for Colorado, and $46 \%$ for Utah site. The 'referent period' for various components of the questionnaire was the year prior to date of diagnosis for cases or date of selection for controls. The following information was collected through the questionnaire: medical history, reproductive history, family history, diet, physical activity, use of tobacco, medication use, diabetes history, and weight history- including birth weight, weight at ages $15,30,50$, and referent year.

Weight was measured at time of interview to the nearest $0.50 \mathrm{lb}$ and height was measured to the nearest 0.25 inches. Weight in pounds was then converted to kilograms and height in inches was converted to meters. The formula used to calculate BMI was weight in kilograms/height in meters ${ }^{2}$. For BMI at referent year, the following international cut-points were used: $<25$ as normal weight, $25-29.9$ as overweight, and 30+ as obese. Waist and hip circumferences were measured and recorded at time of interview to the nearest 0.5 inches. An extensive diet history questionnaire was used to obtain dietary intake data and was adapted to include common foods from the Southwestern area of the US [41] . A modified version of the Cross Cultural Activity Participation Survey (CAPS) [44] was used to collect physical activity data for activities performed at home, work, and during leisure, and for intensity and frequency during referent year and for ages 15,30 and 50 . For referent year, total MET minutes of activity were also calculated and were reported as MET values $[41,45]$.

Menstrual status on the referent date was recorded as follows: (1) I was still having periods and not going through menopause or the change of life; (2) I was still 
having periods but possibly going through menopause or the change of life; (3) I was going through menopause or the change of life; (4) my periods had stopped by themselves; (5) I had an operation which stopped by periods; (6) I was still having periods and on HRT; (7) I was taking medication that had stopped my periods; (8) I was pregnant or my pregnancy ended within 2 months of then or I was nursing. Women were coded as pre/perimenopausal if they reported "yes" to answers $1,2,3$, or 8 and postmenopausal if they answered "yes" to answers 4,5 , or 7 . Women who were 57 years of age or younger at the reference date and who responded "yes" to 6 were classified as premenopausal; and women who were older than 57 years at reference date and responded "yes" to 6 were classified as postmenopausal. Also, women who were classified as postmenopausal were further categorized based on their recent exposure to hormones either through use of HRT or from recent menopause experience. "Recent hormone exposure" was considered if the subject had used HRT within the past 2 years or if they were pre- or peri-menopausal during the two years prior to the referent date, while all other postmenopausal women were classified as not recently exposed to hormones [41].

\section{Genotyping}

Blood samples were collected and DNA was extracted for $75 \%$ of the New Mexico sample, $76.6 \%$ of participants in Arizona, $74.8 \%$ of participants in Colorado, and $93.6 \%$ of participants in Utah. Genotyped DNA from the 4-CBCS was used to assay 11 SNPs from candidate genes; as previously mentioned, these SNPs were selected based upon their suspected role in pathways that connect the energy balance and obesity association with breast cancer. The IRS1 (G972R) and ADRB3 W64R (T>C) variant 
were assayed using the PCR and digestion with BSTN1. The IRS2 G1057D, interleukin 6 SNPs rs 1800797 , rs1800796, and rs2069849 polymorphism were identified using the TaqMan assay [32]. Estrogen receptor alpha (ESR1) $351 \mathrm{~A}>\mathrm{G}$ was genotyped using PCR and Xbal restriction. The IGFBP3 -202 C $>$ A substitution was assessed by PCR and digestion with Alw211 restriction enzyme. Sex hormone binding globulin (SHBG) D327N ( $\mathrm{G}>\mathrm{A})$ variant was assessed using PCR and digestion with Hinfl restriction. Vitamin D receptor (VDR) Bsm1 rs154410 and Fok1 (T>C SNP, rs 10735810 were assayed using PCR and restriction fragment length polymorphism methods [32].

Fifteen markers were identified to characterize genetic admixture. The following markers were amplified using PCR and fluorescently labeled primers with the ABI 3700: MID94, MID142, MID218, MID558, MID577, MID743, MID919, and MID1656. Markers MID152, MID237, MID856, MID944, and MID1469 were amplified by PCR and size fractioned on $3-4 \%$ Nusieve agarose gels and visualized using ethidium bromide staining. The remaining marker, TSC001075 (rs713366) was an anonymous C/T SNP that was genotyped using TaqMan assay (ABI Assays, GA, USA) [32]. The calculation for genetic admixture was based on a two population model that included European and Native ancestry using the program STRUCTURE 2.0 [32, 46-47].

For this dissertation, the ADRB2 SNPs were assayed using the TaqMan assay (Applied Biosystems, Foster City, CA, USA) and were assessed using PCR technology. Each 5ul PCR reaction contained 20 ng of genomic DNA, primers, probes, and TaqMan Universal PCR Master Mix (containing AmpErase UNG, AmpliTaq Gold enzyme, dNTPs, and reaction buffer). PCR was carried out under the following conditions: $50^{\circ} \mathrm{C}$ for 2 minutes to activate $\mathrm{UNG}, 95^{\circ} \mathrm{C}$ for $10 \mathrm{~min}$, followed by 40 cycles of $92^{\circ} \mathrm{C}$ for 15 
sec, and $60^{\circ} \mathrm{C}$ for 1 minute using 384 well duel block ABI 9700. Fluorescent endpoints of the TaqMan reactions were measured using an ABI 7900HT sequence detection instrument.

\section{Independent Variables}

The ADRB2 variants were also studied in terms of their genotypes. The suspected disease causing variants for the two ADRB2 SNPs are Arg16 (Minor allele A) and Glu27 (Minor allele G). The homozygous wild types were used as the referent categories. Associations for the heterozygote genotypes were analyzed, in conjunction with the homozygous variant genotypes. Dominant and recessive model associations for rs1042713 (Arg 16Gly) and rs 1042714 (Gln27Glu) were also investigated. Haplotypes between the two ADRB2 polymorphisms were analyzed as well.

\section{Dependent Variable}

Breast cancer diagnosis for this study includes all incident invasive or in situ breast cancer cases from the 4-CBCS.

\section{Confounding Variables}

Various risk factors have been found to be historically associated with breast cancer, among other risk factors that are believed to contribute to disease risk. It is important to consider these risk factors as potential confounders or covariates, and to adjust for those found to be significant in analyses. The cases and controls have already been frequency matched based upon ethnicity and 5 year age group. Other adjustments

should be considered for the following variables based on their relevance in the previous 
literature cited within this proposal. Age was analyzed as a continuous variable. As previously mentioned, the two ethnic/racial groups within this study are non-Hispanic whites and Hispanics. Education level, which can be used as a surrogate marker for socio-economic status, was categorized as the following: high school or less, some college, bachelor degree or higher. Aspirin usage is coded as 'Yes or No' based upon the question: Before referent year did you ever take aspirin on a regular basis?" NSAID usage is also coded as 'Yes or No' based upon the question: Before referent date did you take non-steroidal anti-inflammatory drugs on a regular basis? Height was measured to the nearest 0.25 inches and was converted to centimeters. The formula used to calculate BMI was weight in kilograms/height in meters ${ }^{2}$. For BMI at referent year, the following international cut-points were used: $<25$ as normal weight, 25-29.9 as overweight, and 30+ as obese. Waist and hip circumferences were measured and recorded at time of interview to nearest 0.5 inches. WHR was categorized as $<0.8,0.8-0.9$, and $>0.9$. Waist circumference was converted to centimeters, and was categorized into quartiles based upon the distribution of the data: $<77.7,77.7-86.5,86.6-97.7$, and $\geq 97.7$. Age at menarche was categorized by the following age groups: $<12,12,13$, and 14 plus. Menopausal status was analyzed in two groups consisting of pre/peri-menopausal and postmenopausal women based upon the algorithm previously described. Parity was categorized in the following groups: nulliparous, 1-2, 3-4, and 5 plus. Smoking status was categorized as current smoker, former smoker, never smoked regularly OR ever smoked vs. never smoked. Physical activity was measured by the total METs. METs are defined as the metabolic equivalent of the task and were calculated based upon the amount, intensity, and duration of activities performed during the referent year. The METs were 
then assigned to each activity based on the Compendium of Physical Activities [48]. The variable used for analysis is total MET hrs/week=(total MET hours/week of moderate physical activity + total MET hours/week of vigorous physical activity) and was analyzed as a continuous variable. Caloric/energy intake per day was analyzed as a continuous variable. Family history of breast cancer 'Yes or No' was based upon a family history of breast cancer in a first degree relative, i.e. parent, sibling, or offspring. Diabetes history was categorized as 'Yes', 'borderline', or 'No' based upon the question "Ever told before referent date that you had diabetes or high blood sugar?" Specific cutpoints for those variables that are categorized are based upon previous literature from the 4-CBCS study. The percentage of genetic admixture was analyzed as a continuous covariate based on the genotypes for ancestry-informative markers previously collected with the parent study [32]. Bias from genetic admixture is possible in studies with populations that have a mixture of genetic heritage from one population with low incidence of a disease and a second with high incidence. As a result, a polymorphism that is more common in the high incidence population can appear to be associated with disease in the admixed population, when in actuality there is no causal association [32, 49]. Study site, also known as center, was also included as a covariate to help control for different proportion of cases and controls interviewed at each center [27, 32, 41].

\section{Methods of Data Analyses}

\section{Cohort Description}

Data analysis was performed using SAS version 9.2 (SAS Institute, Cary NC). Descriptive statistics were calculated for all covariates. The following descriptive 
statistics were reported for continuous covariates such as age, BMI, height, WHR, waist circumference, total METs, and calories consumed: mean, standard deviation, and pvalues for t-tests. These reports were calculated for the overall sample as well as between cases and controls. The categorical variables (such as ethnicity, education, age categorized at menarche, aspirin use, NSAID use, parity, menopausal status, recent estrogen use, family history, BMI-category, WHR-category, WC-category, cigarette smoking status, and other previously mentioned insulin/obesity related variants) were reported as frequencies, percentages, as well as by case-control status and ethnicity. For the case- control comparison, the Mantel-Haenszel Chi-Square test was utilized to test for significant differences between the two groups.

Genotype distributions of the SNPs rs 1042714 (Gln27Glu) and rs1042713 (Arg16Gly) were also conducted for the total sample and by case vs. control status by ethnicity. Frequencies and percentages were reported, in addition to $\mathrm{p}$ values calculated by the Pearson chi-square test to test for significant differences between the two groups. Genotype distributions were also evaluated for agreement with Hardy-Weinberg equilibrium (HWE) by the Pearson chi-square test among controls.

\section{Finding Predictors and Logistic Regression}

Univariable analyses was conducted using logistic regression to test all potential confounders with a significance level of $\mathrm{p}$ value (alpha level) $\leq 0.20$, with final models including variables with significance levels of $p<0.05$. The univariable analyses were also stratified by ethnicity. The model used was an unconditional logistic regression model because the controls are not fully matched with the cases. 
Let $p=$ probability of being case; and $p_{0}=(1-p)=$ probability of being control; $\operatorname{logit}(p)=\log (p / 1-p)$

Example of univariable model: $\operatorname{logit}(p)=\mathrm{b}_{0}+\mathrm{b}_{1} \mathrm{X}$; with $\mathrm{X}=$ covariate(s) of interest A multivariable model was constructed using logistic regression and confidence intervals were reported based upon the significant univariable predictors. Those deemed as covariates were adjusted for in the multivariable logistic regression models after comparing the log likelihood of each model with and without the covariates of interest and the percent of change between the point estimates. Genotype and haplotype association tests for SNPs rs1042714 (Gln27Glu) and rs1042713 (Arg16Gly) were reported as crude odds ratios (ORs), 95\% Confidence Intervals (CIs) determined by unconditional logistic regression. Genotype and haplotype association tests for the same SNPs were then reported with adjusted ORs and CIs that were adjusted for significant covariates from the univariable and multivariable analyses. Codominant models were first analyzed, evaluating the ADRB2 SNPs as a three-level categorical variable; these codominant models are dependent upon the rarity of the variant genotype. Dominant models (homozygous wild type $v s$. heterozygous + homozygous variant) were also used comparing the variant carriers with the referent homozygous wild type. Recessive models (homozygous wild type + heterozygous $v$. homozygous variant) were computed to compare the homozygous variant with all other genotypes for that SNP.

The multivariable logistic regression model was based on the following:

$$
\operatorname{logit}(p)=b_{0}+b_{1} x_{1}+b_{2} x_{2}+b_{3} x_{3}+\ldots+b_{k} x_{k}
$$


Example of full model with all covariates of interest:

$\operatorname{Logit}(p)=b_{0}+b_{1}\left(\operatorname{rs} 1042713(\right.$ Arg 16Gly $)[G / G+G / A$ vs. A/A $)+b_{2}($ age $)+b_{3}($ ethnicity $)+$ $\mathrm{b}_{4}($ education $)+\mathrm{b}_{5}($ aspirin usage $)+\mathrm{b}_{6}$ (NSAID usage $)+\mathrm{b}_{7}$ (height $)+\mathrm{b}_{8}(\mathrm{BMI})+\mathrm{b}_{9}($ WHR $)$

$+b_{10}(W C)+b_{11}($ menstruation start age $)+b_{12}$ (menopausal status $)+b_{13}$ (age at first birth $)+$ $b_{14}($ smoking $)+b_{15}$ (physical activity $)+b_{16}($ caloric intake $)+b_{17}($ family history $)+$ $b_{18}($ diabetes $)+b_{19}($ IRS- 1$)+b_{20}($ IRS- 2$) \ldots b_{k}\left(X_{k}\right)$

(Note: the full model has all covariates of interest, however, variables highly correlated, such as height and BMI, were not modeled together, and only one of the significant covariates, i.e. BMI, from the univariable analyses were used for multivariable modeling).

Haplotype analysis for ADRB2 SNPs rs 1042714 (Gln27Glu) and rs 1042713 (Arg16Gly) was conducted using PROC Haplotype in SAS. A haplotype is defined as a combination of alleles at multiple loci on a single chromosome and a pair of haplotypes comprises the multilocus genotype. Using the expectation-maximization (EM) algorithm, SAS generates the maximum likelihood estimates of haplotype frequencies based on the multilocus sample of the genotypes under the Hardy-Weinberg equilibrium (HWE) assumption. With the Linkage Equilibrium method for initialization to estimate haplotype frequencies, SAS outputs all the haplotype combinations, for each individual as probability scores based on their genotypes. These probabilities are used in regression models with epidemiological association studies. Haplotype probabilities that were unambiguously resolved were categorized into haplotype dose variables for each subject. Individuals with ambiguous haplotypes were those who were not genotyped for one of 
the SNPs. These individuals were excluded from haplotype analyses $(n=191)$. Values of haplotype dose are listed as follows: "0" equaling zero copies, indicating this haplotype is not possible for this individual, " 1 " equaling one copy, indicating heterozygosity at one marker, and "2" equaling two copies, indicating homozygosity for the haplotype $[33,50]$.

Multiplicative interaction models were used to determine the statistical interactions between the 2 SNPs of interest and significant haplotypes with the hypothesized effect modifiers including family history, ethnicity, obesity, menopausal status, and functional SNPs in the following insulin/obesity related genes: IRS1, IRS2, IGF1, ADRB3, and IL6 variants.

Example: logit $(p)=b_{0}+b_{1}($ ADRB2 SNP $)+b_{2}(B M I /$ obese $)+b_{3}($ SNP x BMI/obese $)$

The presence of interaction was tested using the chi-square p-value for interaction $<0.05$. The formal test for interaction between the variables of ethnicity and polymorphisms/haplotypes was evaluated using the difference in maximum likelihood estimates for logistic regression models with and without the constructed ethnicity specific- polymorphism/haplotype variable, using a chi-square test with two degrees of freedom. The test for effect modification using specific strata for potential effect modifiers may have been limited by the sample size, but included stratification by ethnicity, obesity, history of diabetes, and recent hormone exposure. An informal test of interaction was conducted by performing this type of stratification to evaluate if odds ratios differed between the strata for each hypothesized effect modifier. P values for heterogeneity were calculated for differences in association between non-Hispanic white and Hispanic women by comparing the difference in maximum likelihood estimates for a logistic regression model with and without an interaction term between ethnicity and the 
genotype/haplotypes of interest using a chi-square test with one degree of freedom. Multinomial regression models were used to evaluate the associations of the tumor characteristics of ER status.

Multinomial Regression Equation:

Where $p_{0}=(0)$ control, $p_{l}=(1)$ ER $(+)$ case, and $p_{2}=(2)$ ER $(-)$ case

$\mathrm{X}_{\mathrm{i}}=\mathrm{ADRB} 2 \mathrm{SNP} /$ haplotype and $\mathrm{X}_{2} \ldots=$ other covariates

$\operatorname{logit}\left(p_{l}\right)=b_{0}+b_{1}\left(\right.$ ADRB2 SNP) $+b_{2} X_{2} \ldots$

$\operatorname{logit}\left(p_{2}\right)=b_{0}+b_{1}($ ADRB2 SNP $)+b_{2} X_{2} \ldots$

\section{Sample Size and Statistical Power Calculation}

Power calculation was determined with the sample size of $N=3,908$; cases $=1,850$ $(1,244$ non-Hispanic white, 606 Hispanic $)$ and controls $=2,058(1,330$ non-Hispanic white, 728 Hispanic). Equations for Sample size for 2 Binomials were used, where $\mathrm{p}_{0}=$ the number of controls with the genotype of interest (ex. A/A) divided by the total number of controls, and $p_{1}=$ the number of cases with the genotype of interest (ex. A/A) divided by the total number of cases [51]. For a specific example the variant rs 1042713 (Arg 16Gly) will be used. The suspected disease causing genotype using the recessive model for rs 1042713 (Arg 16Gly) is the A/A genotype. The A/A genotype will be denoted as ' 2 ', the $\mathrm{G} / \mathrm{A}$ genotype will be denoted as ' 1 ', and $\mathrm{G} / \mathrm{G}$ genotype will be denoted as ' 0 '. For the dominant model, 0 vs. $1+2$ scheme will be assessed, where $1+2=\mathrm{G} / \mathrm{A}+\mathrm{A} / \mathrm{A}$ vs. $0=\mathrm{G} / \mathrm{G}$. As previously mentioned, for controls $\mathrm{p}_{0}=$ proportion of $\mathrm{A} / \mathrm{A}$, therefore $1-\mathrm{p}_{0}=$ $\mathrm{G} / \mathrm{A}+\mathrm{G} / \mathrm{G}$ in controls. And for cases $\mathrm{p}_{1}=$ proportion of $\mathrm{A} / \mathrm{A}$, therefore $1-\mathrm{p}_{1}=\mathrm{G} / \mathrm{A}+\mathrm{G} / \mathrm{G}$ 
in cases. Conversely, power calculations for the recessive models will be determined, using the $0+1$ vs. 2 scheme, with $0+1=G / G+G / A$ and $2=A / A$. For controls $\mathrm{p}_{0}=$ proportion of $\mathrm{A} / \mathrm{A}+\mathrm{G} / \mathrm{A}$, therefore $1-\mathrm{p}_{0}=$ proportion of $\mathrm{G} / \mathrm{G}$ in controls. And for cases $\mathrm{p}_{1}=$ proportion of $\mathrm{A} / \mathrm{A}+\mathrm{G} / \mathrm{A}$, therefore $1-\mathrm{p}_{1}=$ proportion of $\mathrm{G} / \mathrm{G}$ in cases.

Under the null hypothesis, we assumed these two proportions are equal, i.e. $\mathrm{H}_{0}$ : $\mathrm{p}_{0}=\mathrm{p}_{1}$. Under the alternative hypothesis, we assumed that the minor allele homozygous genotype causes breast cancer, therefore under $\mathrm{H}_{\mathrm{a}}: \mathrm{p}_{\mathrm{l}}>\mathrm{p}_{0}$. There are three approaches for comparing these two hypotheses: 1) based on difference between the proportion, where $\left.\mathrm{p}_{1}-\mathrm{p}_{0} ; 2\right)$ based on relative risk where $\mathrm{p}_{1} / \mathrm{p}_{0} ;$ or 3 ) based on odds ratio where $\left[\mathrm{p}_{1} / 1-\mathrm{p}_{1}\right] /$ $\left[\mathrm{p}_{0} / 1-\mathrm{p}_{0}\right]$. For power calculation purposes, the relative risk $\left(\mathrm{RR}=\mathrm{p}_{\mathrm{l}} / \mathrm{p}_{0}\right)$ approach was used.

In published literature and online sources [52], the frequency of the minor alleles of interest are available, however, we needed to find the frequency of the genotypes to estimate the distribution of these genotypes in our population or sample of women. In order to calculate $\mathrm{p}_{0}$ and $\mathrm{p}_{1}$, the incidence of breast cancer in the general population is also of importance and was found by an online source provided by the SEER data [53]. See Example below:

Example using variant rs 1042713 (Arg16Gly), with minor allele 'A' frequency $(\mathrm{MAF})=0.325$ from data collected from HapMap.org [52] ; frequency of 2 genotype $=\mathrm{A} / \mathrm{A}=(0.325 \times 0.325)=0.106 ;$ Total Sample $=3,908($ cases $=1,850$, controls $=$ $2,058)$ 
Displayed below are the calculations for $R R=1.5$ when model $=$ ' $0+1$ vs. 2 '. We are assuming the controls represent the standard population.

Equation 1: $\mathrm{w}_{0} \mathrm{p}_{0}+\mathrm{w}_{1} \mathrm{p}_{1}=0.106 ; \quad$ with $\mathrm{w}_{0}=1-\mathrm{w}_{1}$

$\mathrm{w}_{1}=$ incidence of breast cancer from general population according to SEER [53] $\mathrm{w}_{1}=0.12$ weight for cases; and $\mathrm{w}_{0}=0.88$ weight for controls

Equation $2: \mathrm{RR}=1.5=\mathrm{p}_{1} / \mathrm{p}_{0} ; \quad$ therefore $\mathrm{p}_{1}=1.5 \mathrm{p}_{0}$

Using Equation 1: $\quad 0.88 \mathrm{p}_{0}+0.12\left(1.5 \mathrm{p}_{0}\right)=0.106$

$0.88 \mathrm{p}_{0}+0.183 \mathrm{p}_{0}=0.106$

$1.06 \mathrm{p}_{0}=0.106$

Therefore $\mathrm{p}_{0}=0.10$ and $\mathrm{p}_{1}=(0.10) 1.5=0.15$.

Table $1 \mathrm{~A}$ and $\mathrm{B}$ display the distribution of genotypes and $\mathrm{p}_{0}, \mathrm{p}_{1}$ values for ADRB2 when $\mathrm{RR}=1.2,1.5$, and 1.75 .

Table $1 \mathrm{~A}$ and $1 \mathrm{~B}$

A. Proportion Values for Recessive Model " $0+1$ vs. 2"

\begin{tabular}{|c|c|c|c|c|c|c|c|c|c|c|}
\hline \multirow[t]{3}{*}{ SNP } & \multirow{3}{*}{$\begin{array}{l}\text { Minor } \\
\text { Allele } \\
\text { Freq }\end{array}$} & \multirow{3}{*}{$\begin{array}{l}\text { Freq } \\
\mathrm{G} / \mathrm{G}=0\end{array}$} & \multirow{3}{*}{$\begin{array}{l}\text { Freq } \\
G / A=1\end{array}$} & \multirow{3}{*}{$\begin{array}{l}\text { Freq } \\
\mathrm{A} / \mathrm{A}=2\end{array}$} & \multicolumn{6}{|c|}{$" 0$ vs. $1+2 "$} \\
\hline & & & & & \multicolumn{2}{|c|}{1.2} & \multicolumn{2}{|c|}{1.5} & \multicolumn{2}{|c|}{1.75} \\
\hline & & & & & $P_{0}$ & $P_{1}$ & $P_{0}$ & $P_{1}$ & $\mathrm{P}_{0}$ & $\mathrm{P}_{1}$ \\
\hline rs 1042713 & 0.325 & 0.456 & 0.439 & 0.106 & 0.10 & 0.12 & 0.10 & 0.15 & 0.10 & 0.17 \\
\hline
\end{tabular}




\section{B. Proportion Values for Dominant Model "0 vs. 1+2"}

\begin{tabular}{|c|c|c|c|c|c|c|c|c|c|c|}
\hline \multirow[t]{3}{*}{ SNP } & \multirow{3}{*}{$\begin{array}{l}\text { Minor } \\
\text { Allele } \\
\text { Freq }\end{array}$} & \multirow{3}{*}{$\begin{array}{l}\text { Freq } \\
G / G=0\end{array}$} & \multirow{3}{*}{$\begin{array}{l}\text { Freq } \\
G / A=1\end{array}$} & \multirow{3}{*}{$\begin{array}{l}\text { Freq } \\
\mathrm{A} / \mathrm{A}=2\end{array}$} & \multicolumn{6}{|c|}{$" 0+1$ vs. $2 "$} \\
\hline & & & & & \multicolumn{2}{|c|}{1.2} & \multicolumn{2}{|c|}{1.5} & \multicolumn{2}{|c|}{1.75} \\
\hline & & & & & $\mathrm{P}_{0}$ & $\mathrm{P}_{1}$ & $\mathrm{P}_{0}$ & $P_{1}$ & $P_{0}$ & $\overline{P_{1}}$ \\
\hline rs 1042713 & 0.325 & 0.456 & 0.439 & 0.106 & 0.53 & 0.64 & 0.51 & 0.77 & 0.50 & 0.87 \\
\hline
\end{tabular}

From the $\mathrm{p}_{1}$ and $\mathrm{p}_{0}$ values calculated for ADRB2 SNPs rs 1042714 (Gln27Glu) and rs1042713 (Arg16Gly), the power estimates presented were calculated by formulas utilized by OpenEpi.com [54].

The equations used to calculate the power percentages for this project are based on the continuity-corrected are sine transformation, since the comparisons are between two independent proportions [55]. This method works well with smaller samples and is better for precision. If $X_{i}$ is the binomially distributed random variable with sample size $n_{i}$ and $p_{i}$ is the parameter, and $i=0$ or 1 , the distribution of the arc sine transformation can be approximated with $\sin ^{-1} \sqrt{ }\left(X_{i} / n_{i}\right) \sim N\left(\sin ^{-1} \sqrt{ }\left(p_{i} 1 / 4 n_{i}\right)\right.$. Using the $\mathrm{H}_{0}: \mathrm{p}_{0}=\mathrm{p}_{1}$ against the alternative hypothesis, $\mathrm{H}_{\mathrm{a}}: \mathrm{p}_{1}>\mathrm{p}_{0}$, with equal sample sizes and a significance level $\alpha$ and power $1-\beta, n$ can be estimated as follows: $\left.n=1 / 2\left\{\left(z_{l-\alpha}-z_{\beta}\right) / \sin ^{-1} \sqrt{ } p_{0^{-}} \sin ^{-1} \sqrt{ } p_{l}\right)\right\}^{2}[55]$. For an accurate estimate of power, the continuity-corrected version of the arc sine transformation can be used: $\left(z_{l-\alpha}-z_{\beta}\right)^{2}=2 n\left\{\sin ^{-1} \sqrt{ }\left(p_{0^{-}}-1 / 2 n\right)-\sin ^{-1} \sqrt{ }\left(p_{l}+1 / 2 n\right)\right\}^{2}[55]$. A final equation can be derived for sample size $n=\left\{Z+\sqrt{ }\left(Z^{2}+2 c \Delta\right)\right\}^{2} / 8 \Delta^{2}$; where $Z=\left(z_{l-\alpha^{-}}\right.$ $\left.z_{\beta}\right), \Delta=\left(\sin ^{-1} \sqrt{ } p_{0^{-}} \sin ^{-1} \sqrt{ } p_{l}\right)$ and $c=\left\{\left(p_{0} q_{0}\right)^{-1}+\left(p_{l} q_{l}\right)^{-1 / 2}\right\}$ [55]. OpenEpi was another method used to calculate the power for this project. The following equation was used by OpenEpi to calculate the power using the power with continuity correction method [54]: 


$$
\text { Power }=\Phi\left(\frac{\sqrt{\left(n * \Delta^{2}\right)-z_{1-\alpha / 2} \sqrt{(1+1 / \kappa) * p^{*} q}}}{\sqrt{\left(p_{1} * q_{1}\right)+\left(p_{2} * q_{2} / \kappa\right)}}\right)
$$

Where $\mathbf{n}^{\prime}=\mathrm{n}_{1}-[(\kappa+1) /(\kappa . \Delta)]$;

Tables $2 \mathrm{~A}$ and B display the power percentages for the overall sample based upon the $p_{0}, p_{1}$ values for the 2 SNPs of interest when $R R=1.2,1.5$, and 1.75 .

\section{Tables $2 A$ and $B$}

\section{A. Power Analysis for 4-CBCS ( $n=3,908)$ for Recessive Model " $0+1$ vs. 2"}

\begin{tabular}{|l|l|l|l|l|l|l|l|l|l|l|}
\hline \multirow{2}{*}{ SNPS } & \multirow{2}{*}{} & MAF & \multicolumn{9}{|c|}{ Model: “0+1 vs. 2" } \\
\cline { 3 - 11 } & & \multicolumn{3}{|c|}{$\mathrm{RR}=1.2$} & \multicolumn{3}{c|}{$\mathrm{RR}=1.5$} & \multicolumn{3}{c|}{$\mathrm{RR}=1.75$} \\
\cline { 2 - 11 } & $\mathrm{P}_{0}{ }^{3}$ & $\mathrm{P}_{1}^{7}$ & Power & $\mathrm{P}_{0}$ & $\mathrm{P}_{1}$ & Power & $\mathrm{P}_{0}$ & $\mathrm{P}_{1}$ & Power \\
\hline $\begin{array}{l}\text { ADRB2 } \\
\text { rs1042713 }\end{array}$ & 0.325 & 0.10 & 0.12 & 0.52 & 0.10 & 0.15 & 0.99 & 0.10 & 0.17 & 1 \\
\hline $\begin{array}{l}\text { ADRB2 } \\
\text { rs1042714 }\end{array}$ & 0.467 & 0.21 & 0.26 & 0.89 & 0.21 & 0.31 & 1 & 0.20 & 0.35 & 1 \\
\hline
\end{tabular}

${ }^{1} \cdot 0=$ homozygous wild type; $1=$ heterozygous; $2=$ homozygous variant

${ }^{2} \mathrm{MAF}=$ Minor allele frequency from Hapmap.org. [52]

${ }^{3} \mathrm{p}_{0}=$ the estimated proportion of controls with variant of interest calculated from Equation 1.

${ }^{4} \mathrm{p}_{\mathrm{I}}=$ the estimated proportion of cases with variant of interest calculated from Equation 1 and Equation 2. 
B. Power Analysis for 4-CBCS ( $n=3,908)$ for Dominant Model "0 vs. $1+2$ "

\begin{tabular}{|c|c|c|c|c|c|c|c|c|c|c|}
\hline \multirow[t]{3}{*}{ SNPS } & \multirow[t]{3}{*}{$\mathrm{MAF}^{2}$} & \multicolumn{9}{|c|}{ Model: "0 vs. $1+2$ "I } \\
\hline & & \multicolumn{3}{|c|}{$\mathrm{RR}=1.2$} & \multicolumn{3}{|c|}{$\mathrm{RR}=1.5$} & \multicolumn{3}{|c|}{$\mathrm{RR}=1.75$} \\
\hline & & $\mathrm{P}_{0}$ & $P_{1}$ & Power & $\overline{\mathrm{P}_{0}}$ & $P_{1}$ & Power & $\mathrm{P}_{0}$ & $P_{1}$ & Power \\
\hline $\begin{array}{l}\text { ADRB2 } \\
\text { rs } 1042713\end{array}$ & 0.325 & 0.53 & 0.64 & 1 & 0.51 & 0.77 & 1 & 0.50 & 0.87 & 1 \\
\hline $\begin{array}{l}\text { ADRB2 } \\
\text { rs } 1042714\end{array}$ & 0.467 & 0.70 & 0.84 & 1 & 0.68 & 1.01 & 1 & 0.66 & 1.15 & 1 \\
\hline
\end{tabular}

${ }^{7} \mathrm{C} 0=$ homozygous wild type; $1=$ heterozygous; 2 = homozygous variant

${ }^{2} \mathrm{MAF}=$ Minor allele frequency from Hapmap.org.[52]

${ }^{3} \mathrm{p}_{0}=$ the estimated proportion of controls with variant of interest calculated from Equation 1.

${ }^{4} \mathrm{p}_{\mathrm{l}}=$ the estimated proportion of cases with variants of interest calculated from Equation 1 and Equation 2. 


\section{RESULTS}

A total of 2,574 non-Hispanic white (NHW) ( $n=1,244$ cases, $n=1,330$ controls) and 1,334 Hispanic women ( $n=606$ cases, $n=728$ controls) were included in analyses. Characteristics of the study population by ethnicity and case-control status are shown in Table 3. The majority of women were over the age of 50 years at time of diagnosis, and there was a significant difference between the mean age for Hispanic cases compared to Hispanic controls $(p=0.03)$, with the mean ages of 52.6 years and 54.0 years, respectively. There was also a significant difference for aspirin usage between Hispanic cases and controls ( $p=0.03$ ), as more controls reported history of aspirin use, 142 controls compared to 91 cases. Average body mass index was also significantly different among Hispanics cases and controls ( $\mathrm{p}=0.01$ ), as Hispanic cases were slightly less overweight (mean $\mathrm{BMI}=28.1 \mathrm{~kg} / \mathrm{m}^{2}$ for cases compared to mean $\mathrm{BMI}=29.0 \mathrm{~kg} / \mathrm{m}^{2}$ for controls). Family history with a $1^{\text {st }}$ degree relative was significantly different between ethnic groups, as more NHW women reported a family history of breast cancer compared to Hispanics. Results for family history were also significantly different within both ethnic groups comparing cases vs. controls (Hispanics $p=0.01$; NHW $p=<0.01$ ). With the exception of age at menarche and recent estrogen use, all other covariates were significantly different when comparing Hispanic women to NHW. The majority of Hispanic women only had some high school or less and a larger proportion was diabetic or borderline diabetic, compared to NHW. 
Table 3. Characteristics of Study Population, Stratified by Ethnicity and Case-Control Status, 4-Corners Breast Cancer Study, 1999-2002 $(n=3,908)$.

\begin{tabular}{|c|c|c|c|c|c|c|c|c|c|c|c|}
\hline & \multicolumn{5}{|c|}{ Non-Hispanic White $(n=2,574)$} & \multicolumn{5}{|c|}{ Hispanic $(n=1,334)$} & \multirow[b]{3}{*}{ p value ${ }^{b}$} \\
\hline & \multicolumn{2}{|c|}{ Case } & \multicolumn{2}{|c|}{ Control } & \multirow[b]{2}{*}{ p value ${ }^{a}$} & \multicolumn{2}{|c|}{ Case } & \multicolumn{2}{|c|}{ Control } & \multirow[b]{2}{*}{$\mathrm{p}_{\text {value }}{ }^{a}$} & \\
\hline & No. & $\%$ & No. & $\%$ & & No. & $\%$ & No. & $\%$ & & \\
\hline Total Subjects & 1244 & & 1330 & & & 606 & & 728 & & & \\
\hline Center & & & & & 0.08 & & & & & 0.33 & $<0.001$ \\
\hline Arizona & 171 & 13.6 & 263 & 19.8 & & 123 & 20.3 & 164 & 22.5 & & \\
\hline Colorado & 257 & 20.7 & 218 & 16.4 & & 120 & 19.8 & 132 & 18.1 & & \\
\hline New Mexico & 494 & 39.7 & 496 & 37.3 & & 263 & 43.4 & 251 & 34.5 & & \\
\hline Utah & 322 & 25.9 & 353 & 26.5 & & 100 & 16.5 & 181 & 24.9 & & \\
\hline Education level & & & & & 0.21 & & & & & 0.05 & $<0.001$ \\
\hline High school or less & 310 & 24.9 & 353 & 26.5 & & 348 & 57.4 & 390 & 53.6 & & \\
\hline Some college & 459 & 36.9 & 499 & 37.5 & & 172 & 28.4 & 203 & 27.9 & & \\
\hline Bachelor degree/ higher & 475 & 38.2 & 478 & 35.9 & & 86 & 14.2 & 135 & 18.5 & & \\
\hline Age at menarche, years & & & & & 0.01 & & & & & 0.45 & 0.648 \\
\hline$<12$ & 255 & 20.5 & 235 & 17.7 & & 137 & 22.6 & 148 & 20.3 & & \\
\hline 12 & 332 & 26.7 & 352 & 26.5 & & 160 & 26.4 & 187 & 25.7 & & \\
\hline 13 & 349 & 28.1 & 349 & 26.2 & & 127 & 21.0 & 179 & 24.6 & & \\
\hline $14+$ & 308 & 24.8 & 394 & 29.6 & & 182 & 30.0 & 214 & 29.4 & & \\
\hline Aspirin Usage ${ }^{g}$ & & & & & 0.21 & & & & & 0.03 & $<0.001$ \\
\hline Yes & 279 & 22.4 & 326 & 24.5 & & 91 & 15.0 & 142 & 19.5 & & \\
\hline No & 965 & 77.6 & 1004 & 75.4 & & 515 & 85.0 & 586 & 80.5 & & \\
\hline NSAID Usage ${ }^{h}$ & & & & & 0.84 & & & & & 0.06 & $<0.001$ \\
\hline Yes & 388 & 31.2 & 410 & 30.8 & & 142 & 23.4 & 203 & 30.2 & & \\
\hline No & 856 & 68.8 & 920 & 69.2 & & 464 & 76.6 & 525 & 69.8 & & \\
\hline Parity & & & & & $<0.001$ & & & & & 0.07 & $<0.001$ \\
\hline Nulliparous & 210 & 16.9 & 188 & 14.1 & & 57 & 9.4 & 70 & 9.6 & & \\
\hline $1-2$ & 543 & 43.7 & 541 & 40.7 & & 247 & 40.8 & 251 & 34.5 & & \\
\hline $3-4$ & 400 & 32.2 & 458 & 34.4 & & 217 & 35.8 & 285 & 39.2 & & \\
\hline $5+$ & 91 & 7.3 & 143 & 10.8 & & 85 & 14.0 & 122 & 16.8 & Table & Cont. \\
\hline
\end{tabular}




\begin{tabular}{|c|c|c|c|c|c|c|c|c|c|c|c|}
\hline & \multicolumn{5}{|c|}{ Non-Hispanic White $(n=2,574)$} & \multicolumn{5}{|c|}{ Hispanic $(n=1,334)$} & \multirow[b]{3}{*}{$p$ value ${ }^{b}$} \\
\hline & \multicolumn{2}{|c|}{ Case } & \multicolumn{2}{|c|}{ Control } & \multirow[b]{2}{*}{ p value ${ }^{a}$} & \multicolumn{2}{|c|}{ Case } & \multicolumn{2}{|c|}{ Control } & \multirow[b]{2}{*}{$\mathrm{p}$ value ${ }^{a}$} & \\
\hline & No. & $\%$ & No. & $\%$ & & No. & $\%$ & No. & $\%$ & & \\
\hline Total Subjects & 1244 & & 1330 & & & 606 & & 728 & & & \\
\hline Menopausal status & & & & & 0.07 & & & & & 0.20 & $<0.001$ \\
\hline Pre-/Peri-menopausal & 430 & 34.6 & 415 & 31.2 & & 243 & 40.1 & 267 & 36.7 & & \\
\hline Post-menopausal & 814 & 65.4 & 915 & 68.8 & & 363 & 59.9 & 461 & 63.3 & & \\
\hline Recent estrogen use ${ }^{d}$ & & & & & 0.04 & & & & & 0.23 & 0.1043 \\
\hline Yes & 992 & 79.7 & 1016 & 76.4 & & 468 & 77.2 & 542 & 74.5 & & \\
\hline No & 252 & 20.2 & 314 & 23.6 & & 138 & 22.8 & 186 & 25.6 & & \\
\hline Family history, 1st degree & & & & & $<0.001$ & & & & & 0.01 & 0.0045 \\
\hline Yes & 277 & 22.5 & 201 & 15.4 & & 107 & 18.0 & 90 & 12.7 & & \\
\hline No & 952 & 77.5 & 1106 & 84.6 & & 486 & 82.0 & 617 & 87.3 & & \\
\hline Diabetes history & & & & & 0.42 & & & & & 0.71 & $<0.001$ \\
\hline Yes & 91 & 7.3 & 113 & 8.5 & & 90 & 14.9 & 110 & 15.1 & & \\
\hline Borderline & 22 & 1.8 & 15 & 1.1 & & 12 & 2.0 & 21 & 2.9 & & \\
\hline No & 1130 & 91.0 & 1200 & 90.4 & & 504 & 83.2 & 596 & 82.0 & & \\
\hline Body mass index $(\mathrm{kg} / \mathrm{m} 2)^{c}$ & & & & & 0.30 & & & & & 0.06 & $<0.001$ \\
\hline$<25$ & 578 & 46.5 & 601 & 45.4 & & 198 & 32.7 & 204 & 28.1 & & \\
\hline $25-29.9$ & 370 & 29.7 & 379 & 28.6 & & 212 & 35.0 & 259 & 35.7 & & \\
\hline $30+$ & 296 & 23.8 & 345 & 26.0 & & 196 & 32.3 & 263 & 36.2 & & \\
\hline Waist- Hip- Ratio (WHR) & & & & & 0.44 & & & & & 0.85 & $<0.001$ \\
\hline$<0.8$ & 646 & 51.9 & 707 & 53.2 & & 162 & 26.7 & 199 & 27.3 & & \\
\hline 0.8 to 0.9 & 484 & 38.9 & 511 & 38.4 & & 347 & 57.3 & 413 & 56.7 & & \\
\hline$>0.9$ & 114 & 9.2 & 112 & 8.4 & & 97 & 16.0 & 116 & 15.9 & & \\
\hline Waist circum ference $(\mathrm{cm})$. & & & & & 0.17 & & & & & 0.46 & $<0.001$ \\
\hline$<77.7$ & 368 & 29.9 & 427 & 32.8 & & 95 & 16.0 & 114 & 15.9 & & \\
\hline $77.7-86.5$ & 301 & 24.5 & 315 & 24.2 & & 168 & 28.3 & 184 & 25.7 & & \\
\hline $86.6-97.7$ & 296 & 24.0 & 289 & 22.2 & & 170 & 28.6 & 213 & 29.8 & & \\
\hline$\geq 97.8$ & 266 & 21.6 & 272 & 20.9 & & 161 & 27.1 & 205 & 28.6 & & \\
\hline & & & & & & & & & & Table & Cont. \\
\hline
\end{tabular}




\begin{tabular}{|c|c|c|c|c|c|c|c|c|c|c|c|}
\hline & \multicolumn{5}{|c|}{ Non-Hispanic White $(n=2,574)$} & \multicolumn{5}{|c|}{ Hispanic $(n=1,334)$} & \multirow[b]{3}{*}{ p value ${ }^{b}$} \\
\hline & \multicolumn{2}{|c|}{ Case } & \multicolumn{2}{|c|}{ Control } & \multirow[b]{2}{*}{ p value $^{a}$} & \multicolumn{2}{|c|}{ Case } & \multicolumn{2}{|c|}{ Control } & \multirow[b]{2}{*}{$\mathrm{p}_{\text {value }}{ }^{a}$} & \\
\hline & No. & $\%$ & No. & $\%$ & & No. & $\%$ & No. & $\%$ & & \\
\hline Total Subjects & 1244 & & 1330 & & & 606 & & 728 & & & \\
\hline Cigarette smoking status ${ }^{i}$ & & & & & 0.12 & & & & & 0.45 & $<0.001$ \\
\hline Current smoker & 154 & 12.4 & 163 & 12.3 & & 70 & 11.6 & 92 & 12.6 & & \\
\hline Former smoker & 391 & 31.4 & 365 & 27.4 & & 128 & 21.1 & 159 & 21.8 & & \\
\hline \multirow[t]{2}{*}{ Never smoked } & 699 & 56.2 & 803 & 60.4 & & 408 & 67.3 & 477 & 65.5 & & \\
\hline & Mean & $(\mathrm{sd})$ & Mean & $(\mathrm{sd})$ & p value ${ }^{e}$ & Mean & $(\mathrm{sd})$ & Mean & $(\mathrm{sd})$ & $p_{\text {value }}^{e}$ & p value ${ }^{f}$ \\
\hline Age (yrs) & 55.4 & 11.0 & 56.2 & 12.2 & 0.09 & 52.6 & 11.1 & 54.0 & 12.0 & 0.03 & $<0.001$ \\
\hline Body mass index $(\mathrm{kg} / \mathrm{m} 2)^{c}$ & 26.8 & 6.0 & 27.0 & 6.2 & 0.62 & 28.1 & 6.0 & 29.0 & 6.2 & 0.01 & $<0.001$ \\
\hline Waist circumference (cm.) & 87.1 & 14.6 & 86.6 & 15.0 & 0.41 & 90.9 & 14.2 & 91.8 & 14.6 & 0.25 & $<0.001$ \\
\hline Waist-hip ratio & 0.80 & 0.07 & 0.80 & 0.07 & 0.12 & 0.84 & 0.06 & 0.84 & 0.07 & 0.54 & $<0.001$ \\
\hline Height (cm.) & 163.3 & 6.32 & 162.8 & 6.42 & 0.07 & 157.3 & 6.30 & 157.0 & 6.34 & 0.47 & $<0.001$ \\
\hline Total MET min/wk & 1430 & 1738 & 1486 & 1816 & 0.43 & 1312 & 1940 & 1233 & 1754 & 0.44 & 0.002 \\
\hline Calories (kcal) & 2180 & 1032 & 2101 & 984 & 0.05 & 2737 & 1414 & 2684 & 1439 & 0.50 & $<0.001$ \\
\hline
\end{tabular}

Note: Percentages may not add up to 100 due to rounding.

a Case-control comparison within ethnicity. Mantel-Haenszel chi-square $p$ values from chi-square tests.

${ }^{b}$ Ethnic group comparison, regardless of case-control status. Mantel-Haenszel chi-square $p$ values from chi-square tests.

${ }^{c}$ Body mass index (BMI) calculated as kilograms $(\mathrm{kg}) /$ meters $(\mathrm{m})^{2}$.

${ }^{d}$ Recent hormone exposure, within 2 yrs of referent year (one year prior to date of diagnosis for cases and one year prior to date of selection for controls).

$e$ Case-control comparison within ethnicity. $p$ values from t-tests.

$f$ Ethnic group comparison, regardless of case-control status. $p$ values from t- tests.

${ }^{g}$ Aspirin use based on question: Before referent year did you ever take aspirin on a regular basis?

" Non-steroidal anti-inflammatory drugs (NSAID) use based on question: Before referent date did you take non-steroidal antiinflammatory drugs on a regular basis?

${ }^{i}$ Cigarette smoking status based on several factors including if subject ever smoked 100 cigarettes per day or more and if subject smoked regularly during the referent year. 
Table 4. Test for Hardy Weinberg Equilibrium (HWE) by Ethnicity among Controls for ADRB2 SNPs from the 4-Corners Breast Cancer Study

\begin{tabular}{lllllll}
\hline $\begin{array}{l}\text { ADRB2 } \\
\text { SNPs }\end{array}$ & \multicolumn{3}{c}{ Non-Hispanic White } & \multicolumn{3}{c}{ Hispanic } \\
\hline & $\begin{array}{l}\text { Hetero- } \\
\text { zygosity }\end{array}$ & $\begin{array}{l}\text { Allelic } \\
\text { Diversity }\end{array}$ & $\begin{array}{l}\text { HWE } \\
\text { p- value }\end{array}$ & $\begin{array}{l}\text { Hetero- } \\
\text { zygosity }\end{array}$ & $\begin{array}{l}\text { Allelic } \\
\text { Diversity }\end{array}$ & $\begin{array}{l}\text { HWE } \\
\text { p-value }\end{array}$ \\
\hline rs1042713 & 0.4566 & 0.4643 & 0.4098 & 0.4912 & 0.4918 & 0.9627 \\
rs1042714 & 0.4820 & 0.4905 & 0.3850 & 0.3550 & 0.3560 & 0.9153 \\
\hline
\end{tabular}

Abbreviations: ADRB2-Adrenergic Receptor Beta-2; SNPs-single nucleotide polymorphisms

Hardy Weinberg Equilibrium for each ethnic group was calculated based on the frequency of the two ADRB2 polymorphisms among controls. As demonstrated in Table 4, all $\mathrm{p}$ values for Hispanic and NHW women are greater than 0.05 for both SNPs. With the use of the Haplotype Procedure in SAS, three haplotypes were identified between rs1042713 (Arg16Gly) and rs1042714 (Gln27Glu). The estimated haplotype frequencies based on the study population are as follows: A-G, 0.392; G-C, 0.362; G-G, 0.246. The A-C haplotype yielded an estimated frequency of 0 , and was not analyzed further. The method for calculating the actual haplotype frequencies among the sample has been previously discussed. (See Methods)

The distributions of the two ADRB2 polymorphisms and haplotypes evaluated are shown in Table 5 along with the other genetic markers previously collected for the 4-CBCS. The table is also stratified by ethnicity and case-control status. There was a significant difference between ethnic groups for both ADRB2 polymorphisms, however, genotype proportions did not differ between cases and controls for Hispanics or NHW. Hispanic women did have a slightly higher proportion of the rs 1042713 (Arg16Gly) A/A variant genotype compared to NHW, while NHW women had a higher proportion of the 
rs 1042714 (Gln27Glu) G/G variant genotype. Interestingly, a large proportion of NHW women had 0 copies of the G-G haplotype compared to Hispanic women and a large proportion of Hispanic women had 0 copies of the G-C haplotype compared to NHW. The only polymorphisms within this study that differed by case-control status are found among NHW women and they are IL6 SNPs rs1800797, rs1800796, rs1800795, and rs2069832. 
Table 5. Genotype Characteristics of Study Population, Stratified by Ethnicity and Case-Control Status, 4-Corners Breast Cancer Study, 1999-2002 $(n=3,908)$.

\begin{tabular}{|c|c|c|c|c|c|c|c|c|c|c|c|}
\hline & \multicolumn{5}{|c|}{ Non-Hispanic White $(\mathrm{n}=2,574)$} & \multicolumn{5}{|c|}{ Hispanic $(n=1,334)$} & \multirow[b]{3}{*}{$\mathrm{p}$ value ${ }^{t}$} \\
\hline & \multicolumn{2}{|c|}{ Case } & \multicolumn{2}{|c|}{ Control } & \multirow[b]{2}{*}{ p value $^{a}$} & \multicolumn{2}{|c|}{ Case } & \multicolumn{2}{|c|}{ Control } & \multirow[b]{2}{*}{$p_{\text {value }}{ }^{a}$} & \\
\hline & No. & $\%$ & No. & $\%$ & & No. & $\%$ & No. & $\%$ & & \\
\hline $\begin{array}{l}\text { Total Subjects } \\
\text { ADRB2 (rs1042713) }\end{array}$ & 1244 & & 1330 & & & 606 & & 728 & & & \\
\hline Genotype & & & & & 0.90 & & & & & 0.41 & $<0.001$ \\
\hline G/G, homozygous wild type & 499 & 41.3 & 520 & 39.8 & & 236 & 30.5 & 236 & 33.0 & & \\
\hline $\mathrm{G} / \mathrm{A}$, heterozygous & 535 & 44.3 & 613 & 46.9 & & 346 & 50.1 & 346 & 48.3 & & \\
\hline $\begin{array}{l}\text { A/A, homozygous variant } \\
\text { ADRB2 (rs1042714) }\end{array}$ & 174 & 14.4 & 173 & 13.3 & & 115 & 19.5 & 134 & 18.7 & & \\
\hline Genotype & & & & & 0.62 & & & & & 0.50 & $<0.001$ \\
\hline $\mathrm{C} / \mathrm{C}$, homozygous wild type & 403 & 33.0 & 427 & 32.6 & & 359 & 60.4 & 415 & 58.0 & & \\
\hline $\mathrm{G} / \mathrm{C}$, heterozygous & 591 & 48.4 & 629 & 48.0 & & 202 & 34.0 & 263 & 36.7 & & \\
\hline G/G, homozygous variant & 226 & 18.5 & 255 & 19.5 & & 33 & 5.6 & 38 & 5.3 & & \\
\hline ADRB2 Haplotype A-G & & & & & & & & & & & \\
\hline 0 copies & 539 & 43.3 & 548 & 41.2 & 0.67 & 197 & 32.5 & 250 & 34.3 & 0.54 & $<0.001$ \\
\hline 1 copy & 531 & 42.7 & 609 & 45.8 & & 294 & 48.5 & 344 & 47.3 & & \\
\hline 2 copies & 174 & 14.0 & 173 & 13.0 & & 115 & 19.0 & 134 & 18.4 & & \\
\hline ADRB2 Haplotype G-G & & & & & & & & & & & \\
\hline 0 copies & 815 & 65.5 & 851 & 64.0 & 0.77 & 275 & 45.4 & 330 & 45.3 & 0.65 & $<0.001$ \\
\hline 1 copy & 371 & 29.8 & 446 & 33.5 & & 275 & 45.4 & 319 & 43.8 & & \\
\hline 2 copies & 58 & 4.7 & 33 & 2.5 & & 56 & 9.2 & 79 & 10.9 & & \\
\hline ADRB2 Haplotype G-C & & & & & & & & & & & \\
\hline 0 copies & 440 & 35.4 & 452 & 34.0 & 0.40 & 374 & 61.7 & 429 & 58.9 & 0.43 & $<0.001$ \\
\hline 1 copy & 578 & 46.5 & 623 & 46.8 & & 199 & 32.8 & 261 & 35.9 & & \\
\hline 2 copies & 226 & 18.2 & 255 & 19.2 & & 33 & 5.5 & 38 & 5.2 & & \\
\hline
\end{tabular}




\begin{tabular}{|c|c|c|c|c|c|c|c|c|c|c|c|}
\hline & \multicolumn{5}{|c|}{ Non-Hispanic White $(n=2,574)$} & \multicolumn{5}{|c|}{ Hispanic $(n=1,334)$} & \multirow[b]{3}{*}{ p value ${ }^{b}$} \\
\hline & \multicolumn{2}{|c|}{ Case } & \multicolumn{2}{|c|}{ Control } & \multirow[b]{2}{*}{ p value $^{a}$} & \multicolumn{2}{|c|}{ Case } & \multicolumn{2}{|c|}{ Control } & \multirow[b]{2}{*}{ p value ${ }^{a}$} & \\
\hline & No. & $\%$ & No. & $\%$ & & No. & $\%$ & No. & $\%$ & & \\
\hline Total Subjects & 1244 & & 1330 & & & 606 & & 728 & & & \\
\hline $\begin{array}{l}\text { ADRB3 (W64R; Trp>Arg) } \\
\text { Genotype }\end{array}$ & & & & & 0.49 & & & & & 0.14 & $<0.001$ \\
\hline WW, homozygous wild type & 1056 & 85.8 & 1123 & 84.6 & & 441 & 73.0 & 552 & 76.1 & & \\
\hline WR, heterozygous & 166 & 13.5 & 196 & 14.8 & & 146 & 24.2 & 159 & 21.9 & & \\
\hline $\mathrm{RR}$, homozygous variant & 9 & 0.8 & 8 & 0.6 & & 17 & 2.8 & 14 & 1.9 & & \\
\hline $\begin{array}{l}\text { Androgen Receptor } \\
\text { Genotype }\end{array}$ & & & & & 0.76 & & & & & 0.14 & $<0.001$ \\
\hline WW, homozygous wild type & 308 & 25.0 & 344 & 26.1 & & 226 & 37.7 & 309 & 43.0 & & \\
\hline WR, heterozygous & 596 & 48.5 & 623 & 47.2 & & 278 & 46.3 & 298 & 41.5 & & \\
\hline $\mathrm{RR}$, homozygous variant & 326 & 26.5 & 352 & 26.7 & & 96 & 16.0 & 112 & 15.6 & & \\
\hline $\begin{array}{l}\text { Insulin Receptor Substrate - } \\
\text { IRS1 (G972R) Genotype }\end{array}$ & & & & & 0.99 & & & & & 0.25 & $<0.001$ \\
\hline $\mathrm{G} / \mathrm{G}$, homozygous wild type & 1076 & 87.1 & 1154 & 87.0 & & 542 & 89.7 & 666 & 91.6 & & \\
\hline $\mathrm{G} / \mathrm{R}$, heterozygous & 155 & 12.5 & 169 & 12.7 & & 60 & 9.9 & 59 & 8.1 & & \\
\hline $\mathrm{R} / \mathrm{R}$, homozygous variant & 5 & 0.4 & 4 & 0.3 & & 2 & 0.3 & 2 & 0.3 & & \\
\hline $\begin{array}{l}\text { Insulin Receptor Substrate - } \\
\text { IRS2 (G1057D) Genotype }\end{array}$ & & & & & 0.09 & & & & & 0.91 & $<0.001$ \\
\hline G/G, homozygous wild type & 525 & 42.3 & 544 & 41.0 & & 224 & 37.0 & 263 & 36.2 & & \\
\hline $\mathrm{G} / \mathrm{D}$, heterozygous & 578 & 46.6 & 594 & 44.7 & & 276 & 45.6 & 347 & 47.7 & & \\
\hline $\mathrm{D} / \mathrm{D}$, homozygous variant & 138 & 11.1 & 190 & 14.3 & & 105 & 17.4 & 117 & 16.1 & & \\
\hline $\begin{array}{l}\text { Estrogen Receptor } \\
\text { (ESR1_Xba) }\end{array}$ & & & & & 0.92 & & & & & 0.84 & $<0.001$ \\
\hline xx site present & 518 & 42.1 & 564 & 42.5 & & 303 & 50.2 & 351 & 48.4 & & \\
\hline$X x$ het & 561 & 45.6 & 600 & 45.2 & & 244 & 40.4 & 313 & 43.2 & & \\
\hline XX site absent & 151 & 12.3 & 164 & 12.4 & & 57 & 9.4 & 61 & 8.4 & & \\
\hline & & & & & & & & & & Table & Cont. \\
\hline
\end{tabular}




\begin{tabular}{|c|c|c|c|c|c|c|c|c|c|c|c|}
\hline & \multicolumn{5}{|c|}{ Non-Hispanic White $(n=2,574)$} & \multicolumn{5}{|c|}{ Hispanic $(n=1,334)$} & \multirow[b]{3}{*}{ p value $^{b}$} \\
\hline & \multicolumn{2}{|c|}{ Case } & \multicolumn{2}{|c|}{ Control } & \multirow[b]{2}{*}{ p value ${ }^{a}$} & \multicolumn{2}{|c|}{ Case } & \multicolumn{2}{|c|}{ Control } & \multirow[b]{2}{*}{$\mathrm{p} \mathrm{value}^{a}$} & \\
\hline & No. & $\%$ & No. & $\%$ & & No. & $\%$ & No. & $\%$ & & \\
\hline Total Subjects & 1244 & & 1330 & & & 606 & & 728 & & & \\
\hline $\begin{array}{l}\text { Insulin Growth Factor-1 } \\
(\text { IGF-1) }\end{array}$ & & & & & 0.23 & & & & & 0.60 & 0.045 \\
\hline CA- $19 / 19$ & 509 & 41.7 & 575 & 43.6 & & 236 & 39.3 & 297 & 41.3 & & \\
\hline 19/non-19 & 556 & 45.6 & 594 & 45.0 & & 279 & 46.4 & 319 & 44.4 & & \\
\hline Non-19/non-19 & 155 & 12.7 & 150 & 11.4 & & 86 & 14.3 & 103 & 14.3 & & \\
\hline $\begin{array}{l}\text { Insulin Growth Factor } \\
\text { Binding Protein-3 (IGFBP3) }\end{array}$ & & & & & 0.67 & & & & & 0.09 & $<0.001$ \\
\hline $\mathrm{C} / \mathrm{C}$, homozygous wild type & 351 & 28.5 & 384 & 29.0 & & 226 & 37.4 & 317 & 43.9 & & \\
\hline $\mathrm{A} / \mathrm{C}$, heterozygote & 608 & 49.4 & 658 & 49.6 & & 305 & 50.5 & 318 & 44.0 & & \\
\hline $\begin{array}{l}\text { A/A, homozygous variant } \\
\text { Sex Hormone Binding }\end{array}$ & 273 & 22.2 & 284 & 21.4 & & 73 & 12.1 & 88 & 12.2 & & \\
\hline Globulin (D327N) & & & & & 0.42 & & & & & 0.20 & $<0.001$ \\
\hline $\mathrm{D} / \mathrm{D}$, homozygous wild type & 944 & 76.8 & 1043 & 78.5 & & 510 & 84.3 & 624 & 86.1 & & \\
\hline D/N, heterozygote & 271 & 22.1 & 266 & 20.0 & & 88 & 14.6 & 99 & 13.7 & & \\
\hline $\mathrm{N} / \mathrm{N}$, homozygous variant & 14 & 1.1 & 19 & 1.4 & & 7 & 1.1 & 2 & 0.3 & & \\
\hline Vitamin D receptor Bsm 1 & & & & & 0.62 & & & & & 0.15 & $<0.001$ \\
\hline $0-b b$, site present & 422 & 34.1 & 478 & 36.0 & & 299 & 49.5 & 386 & 53.6 & & \\
\hline 1-bB, heterozygote & 616 & 49.8 & 632 & 47.6 & & 249 & 41.2 & 275 & 38.2 & & \\
\hline $\begin{array}{l}\text { 2-BB, site not present } \\
\text { Vitamin D receptor Poly-A }\end{array}$ & 198 & 16.0 & 219 & 16.5 & & 56 & 9.3 & 59 & 8.2 & & \\
\hline tail & & & & & 0.44 & & & & & 0.23 & $<0.001$ \\
\hline $0-\mathrm{LL}$ & 433 & 35.6 & 491 & 37.2 & & 302 & 50.6 & 397 & 55.1 & & \\
\hline 1-SL heterozygote & 583 & 47.9 & 617 & 46.8 & & 244 & 40.9 & 260 & 36.1 & & \\
\hline 2-SS short variant & 201 & 15.5 & 211 & 16.0 & & 51 & 8.5 & 63 & 8.8 & & \\
\hline Vitamin D receptor Fok1 & & & & & 0.72 & & & & & 0.54 & 0.001 \\
\hline 0 -ff ( 2 start sites $)$ & 179 & 14.5 & 188 & 14.2 & & 101 & 16.7 & 128 & 17.7 & & \\
\hline $1-\mathrm{fF}$ het & 565 & 45.9 & 632 & 47.6 & & 292 & 48.3 & 353 & 48.7 & & \\
\hline 2-FF ( $>$ C polymorphism) & 488 & 39.6 & 508 & 38.3 & & 212 & 35.0 & 244 & 33.7 & Table & Cont. \\
\hline
\end{tabular}




\begin{tabular}{|c|c|c|c|c|c|c|c|c|c|c|c|}
\hline & \multicolumn{5}{|c|}{ Non-Hispanic White $(n=2,574)$} & \multicolumn{5}{|c|}{ Hispanic $(n=1,334)$} & \multirow[b]{3}{*}{$p_{\text {value }}^{b}$} \\
\hline & \multicolumn{2}{|c|}{ Case } & \multicolumn{2}{|c|}{ Control } & \multirow[b]{2}{*}{$\mathrm{p} \mathrm{value}^{a}$} & \multicolumn{2}{|c|}{ Case } & \multicolumn{2}{|c|}{ Control } & \multirow[b]{2}{*}{$\mathrm{p}$ value $^{a}$} & \\
\hline & No. & $\%$ & No. & $\%$ & & No. & $\%$ & No. & $\%$ & & \\
\hline Total Subjects & 1244 & & 1330 & & & 606 & & 728 & & & \\
\hline IL6 (rs1800797) & & & & & 0.003 & & & & & 0.63 & $<0.001$ \\
\hline 0 -wildtype & 464 & 37.7 & 427 & 32.3 & & 411 & 67.9 & 468 & 64.6 & & \\
\hline 1-heterozygote & 573 & 46.5 & 648 & 49.0 & & 164 & 27.1 & 233 & 32.2 & & \\
\hline 2-homozygous variant & 195 & 15.8 & 248 & 18.8 & & 30 & 5.0 & 23 & 3.2 & & \\
\hline IL6 (rs1800796) & & & & & 0.02 & & & & & & $<0.001$ \\
\hline 0 -wildtype & 1074 & 86.5 & 1188 & 89.4 & & 351 & 58.0 & 406 & 55.9 & 0.60 & \\
\hline 1-heterozygote & 161 & 13.0 & 137 & 10.3 & & 209 & 34.6 & 268 & 36.9 & & \\
\hline 2-homozygous variant & 6 & 0.5 & 4 & 0.3 & & 45 & 7.4 & 52 & 7.2 & & \\
\hline IL6 (rs1800795) & & & & & 0.003 & & & & & 0.49 & $<0.001$ \\
\hline 0 -wildtype & 455 & 36.8 & 409 & 30.8 & & 404 & 66.8 & 460 & 63.4 & & \\
\hline 1-heterozygote & 570 & 46.1 & 661 & 49.7 & & 171 & 28.3 & 239 & 32.9 & & \\
\hline 2-homozygous variant & 212 & 17.1 & 259 & 19.5 & & 30 & 5.0 & 27 & 3.7 & & \\
\hline IL6 (rs2069832) & & & & & 0.002 & & & & & 0.51 & $<0.001$ \\
\hline 0 -wildtype & 450 & 36.5 & 406 & 30.7 & & 400 & 66.3 & 457 & 63.0 & & \\
\hline 1-heterozygote & 577 & 46.8 & 660 & 49.9 & & 172 & 28.5 & 241 & 33.2 & & \\
\hline 2-homozygous variant & 207 & 16.8 & 258 & 19.5 & & 31 & 5.1 & 28 & 3.9 & & \\
\hline IL6 (rs2069849) & & & & & 0.85 & & & & & 0.23 & $<0.001$ \\
\hline 0 -wildtype & 1181 & 95.4 & 1268 & 95.6 & & 539 & 89.1 & 632 & 87.2 & & \\
\hline 1-heterozygote & 56 & 4.5 & 58 & 4.4 & & 66 & 10.9 & 91 & 12.6 & & \\
\hline 2-homozygous variant & 1 & 0.1 & 1 & 0.1 & & 0 & 0 & 2 & 0.3 & & \\
\hline
\end{tabular}

$\begin{array}{llll}\text { 2-homozygous variant } & 1 & 0.1 & 1\end{array}$

a Case-control comparison within ethnicity. Mantel-Haenszel chi-square $p$ values from chi-square tests.

${ }^{b}$ Ethnic group comparison, regardless of case-control status. Mantel-Haenszel chi-square $p$ values from chi-square tests. 
Table 6. Characteristics of the ADRB2 Polymorphisms

\begin{tabular}{|c|c|c|c|c|}
\hline SNP & Alleles & Allele Change & Residue Change & $\begin{array}{l}\text { Amino Acid } \\
\text { Name }\end{array}$ \\
\hline rs1042713 & Major: $\mathrm{G}$ & $\mathrm{AGA} \triangleright \mathbf{G G A}$ & $\mathrm{R}[\mathrm{Arg}] \triangleright \mathrm{G}[\mathrm{Gly}]$ & Arg 16Gly \\
\hline rs 1042714 & $\begin{array}{l}\text { Minor: A } \\
\text { Major: C } \\
\text { Minor: G }\end{array}$ & $\mathrm{CAA} \triangleright \mathrm{GAA}$ & $\mathrm{Q}[\mathrm{Gln}] \triangleright \mathrm{E}[\mathrm{Glu}]$ & Gln27Glu \\
\hline
\end{tabular}

Reference: [2]

(Note: Gln-Glutamine, Glu-Glutamic Acid)

Table 6 reports the amino acid changes associated with the major and minor alleles for each ADRB2 polymorphism. Based on this table, the following amino acids are associated with each haplotype: (G-G) haplotype-Gly-Glu; (A-G) haplotype-Arg-Glu; (G-C) haplotype-Gly-Gln; and (A-C) haplotype- Arg-Gln (not discussed).

Univariable Odds Ratios (ORs), 95\% Confidence Intervals $(95 \% \mathrm{CI})$ and $\mathrm{p}$ values are reported for all descriptive covariates and were further stratified by ethnicity in Table 7. Significant covariates with breast cancer association were identified with $\mathrm{p}$ values $\leq$ 0.20. The following characteristics were suggested for multivariable models: age at menarche, parity, family history of breast cancer, recent hormone exposure, aspirin use, smoking status, and body mass index at referent year. History of diabetes was also included in multivariable modeling as it is related to the ADRB2 gene and risk of breast cancer. The univariable odds ratios stratified by ethnicity were comparable for Hispanic and NHW, except for history of diabetes [Hispanic OR=0.68; 95\% CI: 0.33-1.39 vs. NHW OR=1.56;95\%CI: 0.80-3.02].

Table 8 reports the univariable results for the ADRB2 polymorphisms, ADRB2 haplotypes, and the other polymorphisms collected for the 4-CBCS. Crude ORs and 95\% CIs are also stratified by ethnicity to informally test for any evidence of effect 
modification. Overall, the ADRB2 rs1042713 (Arg16Gly) polymorphism was not associated with breast cancer risk; the $\mathrm{A} / \mathrm{A}$ genotype compared with the homozygous wild type genotype $(\mathrm{G} / \mathrm{G})$ was not statistically significant for the total sample or by ethnic group. When combined with the heterozygous G/A genotype and analyzed against the homozygous $\mathrm{G} / \mathrm{G}$ genotype, results remained non-significant. As with rs 1042713 (Arg16Gly), the ADRB2 rs1042714 polymorphism was also not associated with breast cancer risk. Stratification by ethnicity did not reveal any significant results for the $G / G$ genotype vs. the homozygous wild type $(\mathrm{C} / \mathrm{C})$ genotype or for the combination of the heterozygous $\mathrm{C} / \mathrm{G}$ genotype and $\mathrm{G} / \mathrm{G}$ genotype vs. the homozygous $\mathrm{C} / \mathrm{C}$ wild type. The ADRB2 SNPs were not considered for further analyses due to their non-significant associations. 
Table 7. Univariable Odds Ratios (OR) and 95\% Confidence Intervals for Demographic Characteristics from the 4-Corners Breast Cancer Study

\begin{tabular}{|c|c|c|c|c|c|c|c|}
\hline \multirow[b]{2}{*}{ Variable/Covariates } & \multicolumn{3}{|c|}{$\begin{array}{c}\text { Total } \\
(n=3,908)\end{array}$} & \multicolumn{2}{|c|}{$\begin{array}{l}\text { Non-Hispanic White } \\
(n=2,574)\end{array}$} & \multicolumn{2}{|c|}{$\begin{array}{c}\text { Hispanic } \\
(\mathrm{n}=1,334)\end{array}$} \\
\hline & OR & $95 \% \mathrm{CI}$ & $\mathrm{P}$ value & OR & $95 \% \mathrm{CI}$ & OR & $95 \% \mathrm{CI}$ \\
\hline \multicolumn{8}{|l|}{ Education } \\
\hline High School or less & Referent & 1.00 & & Referent & 1.00 & Referent & 1.00 \\
\hline Some college & 1.02 & $0.87-1.18$ & 0.98 & 0.88 & $0.73-1.08$ & 1.40 & $1.03-1.90$ \\
\hline Bachelor degree/higher & 1.03 & $0.89-1.21$ & 0.72 & 0.93 & $0.77-1.11$ & 1.33 & $0.95-1.87$ \\
\hline \multicolumn{8}{|l|}{ Age at Menarche } \\
\hline$<12$ & Referent & 1.00 & & Referent & 1.00 & Referent & 1.00 \\
\hline 12 & 0.89 & $0.74-1.08$ & 0.92 & 0.87 & $0.69-1.10$ & 0.92 & $0.68-1.27$ \\
\hline 13 & 0.88 & $0.73-1.06$ & 0.90 & 0.92 & $0.73-1.16$ & 0.77 & $0.55-1.06$ \\
\hline $14+$ & 0.79 & $0.66-0.95$ & 0.03 & 0.72 & $0.57-0.91$ & 0.92 & $0.68-1.25$ \\
\hline $\begin{array}{l}\text { Menopausal Status } \\
\text { (Pre/Peri vs. Post) }\end{array}$ & 1.15 & $1.01-1.32$ & 0.03 & 1.17 & $1.00-1.37$ & 1.16 & $0.93-1.44$ \\
\hline \multicolumn{8}{|l|}{ Parity } \\
\hline Nulliparous & Referent & 1.00 & & Referent & 1.00 & Referent & 1.00 \\
\hline $1-2$ & 0.96 & $0.79-1.17$ & 0.01 & 0.90 & $0.71-1.13$ & 1.21 & $0.82-1.79$ \\
\hline $3-4$ & 0.80 & $0.66-0.98$ & 0.40 & 0.78 & $0.62-0.99$ & 0.94 & $0.63-1.38$ \\
\hline $5+$ & 0.64 & $0.50-0.83$ & $<0.01$ & 0.57 & $0.41-0.79$ & 0.86 & $0.55-1.34$ \\
\hline Family History $(Y / N)$ & 1.58 & $1.34-1.87$ & $<0.01$ & 1.60 & $1.31-1.96$ & 1.51 & $1.11-2.05$ \\
\hline $\begin{array}{l}\text { Recent Exposure to HRT } \\
(\mathrm{Y} / \mathrm{N})\end{array}$ & 1.20 & $1.03-1.40$ & 0.02 & 1.22 & $1.01-1.47$ & 1.16 & $0.90-1.50$ \\
\hline Smoking Status & & & & & & & \\
\hline Ever vs. Never & 1.10 & $0.97-1.26$ & 0.13 & 1.19 & $1.02-1.39$ & 0.92 & $0.73-1.16$ \\
\hline Aspirin usage $(\mathrm{Y} / \mathrm{N})$ & 0.85 & $0.73-0.99$ & 0.04 & 0.89 & $0.74-1.07$ & 0.73 & $0.55-0.97$ \\
\hline NSAID usage $(\mathrm{Y} / \mathrm{N})$ & 0.96 & $0.82-1.09$ & 0.44 & 1.02 & $0.86-1.20$ & 0.79 & $0.62-1.01$ \\
\hline
\end{tabular}




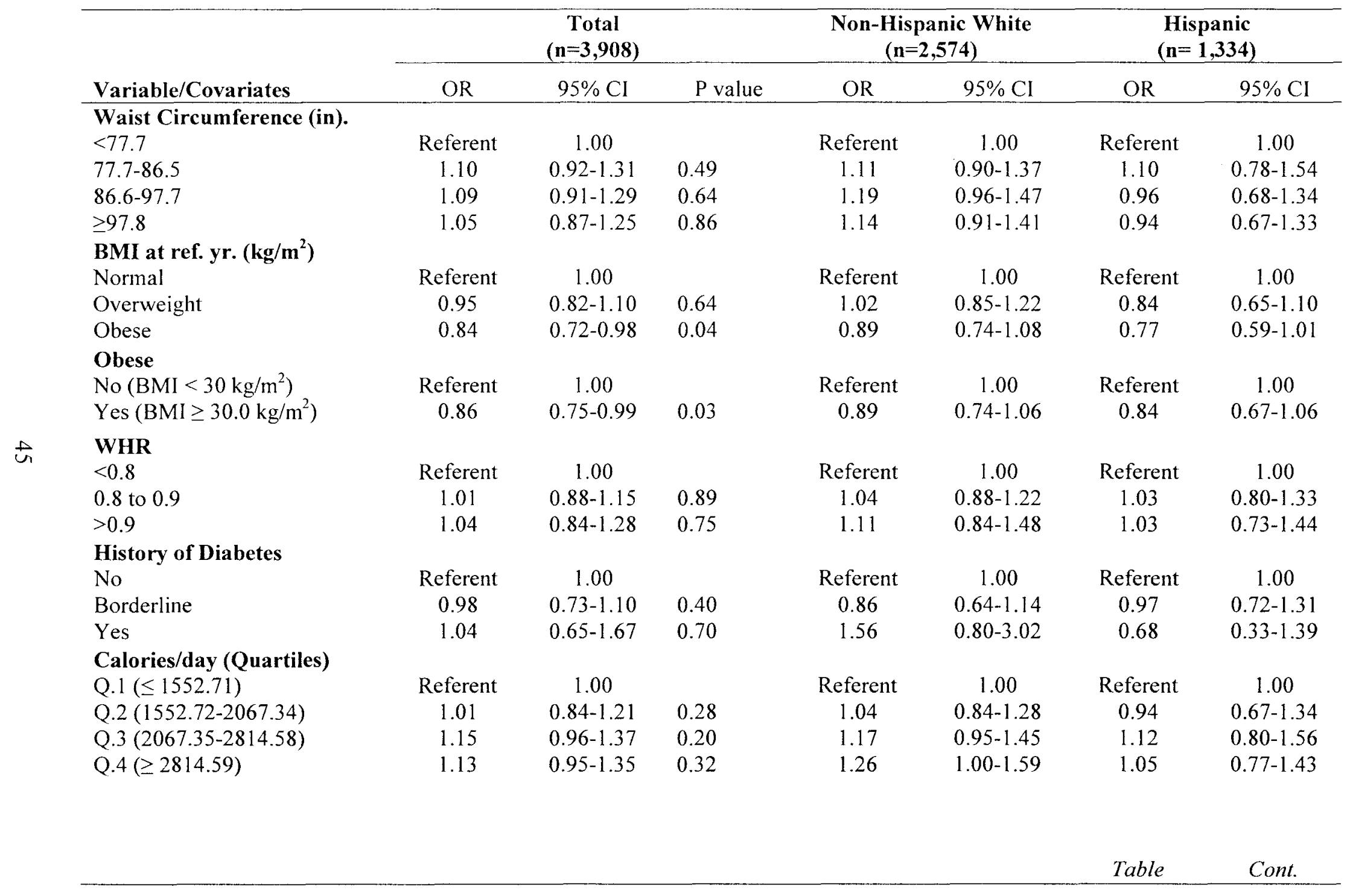




\begin{tabular}{|c|c|c|c|c|c|c|c|}
\hline \multirow[b]{2}{*}{ Variable/Covariates } & \multicolumn{3}{|c|}{$\begin{array}{c}\text { Total } \\
(\mathrm{n}=3,908)\end{array}$} & \multicolumn{2}{|c|}{$\begin{array}{c}\text { Non-Hispanic White } \\
(n=2,574)\end{array}$} & \multicolumn{2}{|c|}{$\begin{array}{c}\text { Hispanic } \\
(n=1,334)\end{array}$} \\
\hline & OR & $95 \% \mathrm{CI}$ & P value & OR & $95 \% \mathrm{CI}$ & OR & $95 \% \mathrm{CI}$ \\
\hline \multicolumn{8}{|l|}{ Total Mets (Quartiles) } \\
\hline Q.1 $(<250.00)$ & Referent & 1.00 & & Referent & 1.00 & Referent & 1.00 \\
\hline Q.2 (250.00-835.55) & 0.94 & $0.77-1.11$ & 0.40 & 0.87 & $0.70-1.10$ & 0.99 & $0.75-1.33$ \\
\hline Q.3 (835.56-1848.78) & 0.97 & $0.81-1.16$ & 0.97 & 0.93 & $0.74-1.16$ & 1.00 & $0.74-1.36$ \\
\hline Q.4 $(>1848.78)$ & 0.98 & $0.82-1.18$ & 0.80 & 0.90 & $0.72-1.13$ & 1.11 & $0.82-1.51$ \\
\hline \multicolumn{8}{|l|}{ Height (Quartiles) } \\
\hline$Q .1(\leq 1.562)$ & Referent & 1.00 & & Referent & 1.00 & Referent & 1.00 \\
\hline Q.2 (1.563-1.610) & 1.27 & $1.06-1.51$ & 0.30 & 1.38 & $1.06-1.80$ & 1.16 & $0.89-1.51$ \\
\hline Q.3 (1.611-1.656) & 1.24 & $1.04-1.48$ & 0.50 & 1.37 & $1.06-1.77$ & 1.05 & $0.78-1.41$ \\
\hline Q.4 ( $\geq 1.657)$ & 1.30 & $1.09-1.55$ & 0.14 & 1.38 & $1.08-1.76$ & 1.24 & $0.84-1.83$ \\
\hline
\end{tabular}


Table 8. Univariable Odds Ratios (OR) and 95\% Confidence Intervals for Genetic Polymorphisms from the 4-Corners Breast Cancer Study

\begin{tabular}{|c|c|c|c|c|c|c|c|}
\hline \multirow[b]{2}{*}{ Variable/Covariates } & \multicolumn{3}{|c|}{$\begin{array}{c}\text { Total } \\
(\mathrm{n}=3,908)\end{array}$} & \multicolumn{2}{|c|}{$\begin{array}{c}\text { Non-Hispanic White } \\
(n=2,574)\end{array}$} & \multicolumn{2}{|c|}{$\begin{array}{c}\text { Hispanic } \\
(n=1,334)\end{array}$} \\
\hline & OR & $95 \% \mathrm{CI}$ & $P$ value & OR & $95 \% \mathrm{CI}$ & OR & $95 \% \mathrm{CI}$ \\
\hline \multicolumn{8}{|l|}{ ADRB2 (rs1042713) } \\
\hline $0-\mathrm{G} / \mathrm{G}$ & Referent & 1.00 & & Referent & 1.00 & Referent & 1.00 \\
\hline $1-\mathrm{G} / \mathrm{A}$ & 0.97 & $0.84-1.11$ & 0.38 & 0.91 & $0.77-1.08$ & 1.12 & $0.88-1.44$ \\
\hline $2-\mathrm{A} / \mathrm{A}$ & 1.05 & $0.87-1.27$ & 0.47 & 1.05 & $0.82-1.34$ & 1.13 & $0.82-1.54$ \\
\hline \multicolumn{8}{|l|}{ ADRB2 (rs1042714) } \\
\hline $0-\mathrm{C} / \mathrm{C}$ & Referent & 1.00 & & Referent & 1.00 & Referent & 1.00 \\
\hline $1-\mathrm{G} / \mathrm{C}$ & 0.98 & $0.86-1.13$ & 0.93 & 1.00 & $0.83-1.19$ & 0.89 & $0.70-1.12$ \\
\hline $2-G / G$ & 0.98 & $0.81-1.19$ & 0.87 & 0.94 & $0.75-1.18$ & 1.00 & $0.62-1.63$ \\
\hline \multicolumn{8}{|l|}{ ADRB2 (rs1042713) } \\
\hline $0-\mathrm{G} / \mathrm{G}$ & Referent & 1.00 & & Referent & 1.00 & Referent & 1.00 \\
\hline $1-\mathrm{G} / \mathrm{A}$ or $\mathrm{A} / \mathrm{A}$ & 0.99 & $0.86-1.12$ & 0.82 & 0.94 & $0.80-1.10$ & 1.12 & $0.89-1.42$ \\
\hline \multicolumn{8}{|l|}{ ADRB2 (rs1042714) } \\
\hline $0-\mathrm{C} / \mathrm{C}$ & Referent & 1.00 & & Referent & 1.00 & Referent & 1.00 \\
\hline \multicolumn{8}{|l|}{ Haplotype A-G } \\
\hline 0 copies & Referent & 1.00 & & Referent & 1.00 & Referent & 1.00 \\
\hline 1 copy & 0.94 & $0.81-1.08$ & 0.28 & 0.89 & $0.75-1.05$ & 1.08 & $0.85-1.38$ \\
\hline 2 copies & 1.02 & $0.85-1.23$ & 0.56 & 1.02 & $0.80-1.30$ & 1.09 & $0.80-1.49$ \\
\hline Continuous A-G & 0.99 & $0.91-1.09$ & 0.89 & 0.98 & $0.87-1.09$ & 1.05 & $0.90-1.22$ \\
\hline \multicolumn{8}{|l|}{ Haplotype G-G } \\
\hline 0 copies & Referent & 1.00 & & Referent & 1.00 & Referent & 1.00 \\
\hline 1 copy & 0.92 & $0.80-1.05$ & 0.12 & 0.87 & $0.73-1.03$ & 1.03 & $0.82-1.30$ \\
\hline 2 copies & 1.10 & $0.84-1.45$ & 0.30 & 1.84 & $1.18-2.84$ & 0.85 & $0.58-1.24$ \\
\hline Continuous G-G & 0.98 & $0.88-1.09$ & 0.67 & 1.02 & $0.89-1.17$ & 0.96 & $0.82-1.13$ \\
\hline
\end{tabular}




\begin{tabular}{|c|c|c|c|c|c|c|c|}
\hline \multirow[b]{2}{*}{ Variable/Covariates } & \multicolumn{3}{|c|}{$\begin{array}{c}\text { Total } \\
(\mathrm{n}=3,908)\end{array}$} & \multicolumn{2}{|c|}{$\begin{array}{c}\text { Non-Hispanic White } \\
(n=2,574)\end{array}$} & \multicolumn{2}{|c|}{$\begin{array}{c}\text { Hispanic } \\
(n=1,334)\end{array}$} \\
\hline & OR & $95 \% \mathrm{Cl}$ & $P$ value & OR & $95 \% \mathrm{CI}$ & OR & $95 \% \mathrm{CI}$ \\
\hline \multicolumn{8}{|l|}{$\begin{array}{l}\text { Hap G-G Model } \\
\text { "0 vs. } 1+2 "\end{array}$} \\
\hline 0 & Referent & 1.00 & & Referent & 1.00 & Referent & 1.00 \\
\hline $1+2$ & 0.94 & $0.83-1.07$ & 0.33 & 0.94 & $0.80-1.10$ & 1.00 & $0.80-1.24$ \\
\hline \multicolumn{8}{|l|}{$\begin{array}{l}\text { Hap G-G Model } \\
\text { "0+1 vs.2" }\end{array}$} \\
\hline $0+1$ & Referent & 1.00 & & Referent & 1.00 & Referent & 1.00 \\
\hline 2 & 1.14 & $0.87-1.49$ & 0.34 & 1.92 & $1.25-2.97$ & 0.84 & $0.58-1.20$ \\
\hline \multicolumn{8}{|l|}{ Haplotype G-C } \\
\hline 0 copies & Referent & 1.00 & & Referent & 1.00 & Referent & 1.00 \\
\hline 1 copy & 0.95 & $0.83-1.09$ & 0.69 & 0.95 & $0.80-1.13$ & 0.88 & $0.69-1.10$ \\
\hline 2 copies & 0.96 & $0.79-1.16$ & 0.83 & 0.91 & $0.73-1.14$ & 1.00 & $0.61-1.62$ \\
\hline Continuous G-C & 0.97 & $0.89-1.06$ & 0.52 & 0.95 & $0.86-1.06$ & 0.93 & $0.78-1.12$ \\
\hline \multicolumn{8}{|l|}{ ADRB3 (Arg64Trp) } \\
\hline 0 & Referent & 1.00 & & Referent & 1.00 & Referent & 1.00 \\
\hline 1 & 0.98 & $0.83-1.16$ & 0.34 & 0.90 & $0.72-1.13$ & 1.15 & $0.89-1.49$ \\
\hline 2 & 1.32 & $0.75-2.34$ & 0.33 & 1.20 & $0.46-3.11$ & 1.52 & $0.74-3.12$ \\
\hline \multicolumn{8}{|l|}{ AR (AR_CAG repeat) } \\
\hline 0 & Referent & 1.00 & & Referent & 1.00 & Referent & 1.00 \\
\hline 1 & 1.16 & $1.00-1.34$ & 0.14 & 1.07 & $0.88-1.29$ & 1.28 & $1.00-1.62$ \\
\hline 2 & 1.11 & $0.93-1.32$ & 0.68 & 1.03 & $0.83-1.28$ & 1.17 & $0.85-1.62$ \\
\hline \multicolumn{8}{|l|}{ ESR1_Xba } \\
\hline 0 & Referent & 1.00 & & Referent & 1.00 & Referent & 1.00 \\
\hline 1 & 0.98 & $0.86-1.12$ & 0.65 & 1.02 & $0.86-1.20$ & 0.90 & $0.72-1.13$ \\
\hline 2 & 1.03 & $0.84-1.27$ & 0.71 & 1.00 & $0.78-1.29$ & 1.08 & $0.73-1.60$ \\
\hline \multicolumn{8}{|l|}{ IGF1 (19CA repeats) } \\
\hline 0 & Referent & 1.00 & & Referent & 1.00 & Referent & 1.00 \\
\hline 1 & 1.07 & $0.94-1.23$ & 0.85 & 1.06 & $0.90-1.25$ & 1.10 & $0.87-1.39$ \\
\hline \multirow[t]{2}{*}{2} & 1.12 & $0.91-1.36$ & 0.44 & 1.17 & $0.91-1.50$ & 1.05 & $0.73-1.47$ \\
\hline & & & & & & Table & Cont. \\
\hline
\end{tabular}




\begin{tabular}{|c|c|c|c|c|c|c|c|}
\hline \multirow[b]{2}{*}{ Variable/Covariates } & \multicolumn{3}{|c|}{$\begin{array}{c}\text { Total } \\
(n=3,908)\end{array}$} & \multicolumn{2}{|c|}{$\begin{array}{c}\text { Non-Hispanic White } \\
(n=2,574)\end{array}$} & \multicolumn{2}{|c|}{$\begin{array}{c}\text { Hispanic } \\
(n=1,334)\end{array}$} \\
\hline & OR & $95 \% \mathrm{Cl}$ & $P$ value & OR & $95 \% \mathrm{CI}$ & OR & $95 \% \mathrm{CI}$ \\
\hline \multicolumn{8}{|l|}{ IGFBP3 $(202 \mathrm{C}>\mathrm{A})$} \\
\hline 0 & Referent & 1.00 & & Referent & 1.00 & Referent & 1.00 \\
\hline 1 & 1.14 & $0.99-1.31$ & 0.31 & 1.01 & $0.84-1.21$ & 1.35 & $1.07-1.70$ \\
\hline 2 & 1.13 & $0.94-1.36$ & 0.48 & 1.05 & $0.84-1.31$ & 1.16 & $0.82-1.66$ \\
\hline \multicolumn{8}{|l|}{ IRS-1 (G972R) } \\
\hline 0 & Referent & 1.00 & & Referent & 1.00 & Referent & 1.00 \\
\hline 1 & 1.06 & $0.87-1.29$ & 0.80 & 0.98 & $0.78-1.24$ & 1.25 & $0.86-1.82$ \\
\hline 2 & 1.31 & $0.44-3.91$ & 0.66 & 1.34 & $0.36-5.00$ & 1.23 & $0.17-8.75$ \\
\hline \multicolumn{8}{|l|}{ IRS-2 (G1057D) } \\
\hline 0 & Referent & 1.00 & & Referent & 1.00 & Referent & 1.00 \\
\hline 1 & 0.98 & $0.85-1.12$ & 0.41 & 1.00 & $0.85-1.19$ & 0.93 & $0.74-1.19$ \\
\hline 2 & 0.85 & $0.70-1.04$ & 0.11 & 0.75 & $0.59-0.97$ & 1.05 & $0.77-1.45$ \\
\hline \multicolumn{8}{|l|}{ SHBG (D327N) } \\
\hline 0 & Referent & 1.00 & & Referent & 1.00 & Referent & 1.00 \\
\hline 1 & 1.13 & $0.96-1.33$ & 0.76 & 1.13 & $0.93-1.36$ & 1.09 & $0.80-1.48$ \\
\hline 2 & 1.15 & $0.62-2.11$ & 0.81 & 0.81 & $0.41-1.63$ & 4.28 & $0.89-20.70$ \\
\hline \multicolumn{8}{|l|}{ VDR_Bsm 1} \\
\hline 0 & Referent & 1.00 & & Referent & 1.00 & Referent & 1.00 \\
\hline 1 & 1.14 & $1.00-1.31$ & 0.20 & 1.10 & $0.93-1.31$ & 1.17 & $0.93-1.47$ \\
\hline 2 & 1.10 & $0.90-1.33$ & 0.80 & 1.02 & $0.81-1.29$ & 1.23 & $0.83-1.82$ \\
\hline \multicolumn{8}{|l|}{ VDR_PolyA tail } \\
\hline 0 & Referent & 1.00 & & Referent & 1.00 & Referent & 1.00 \\
\hline 1 & 1.14 & $0.99-1.31$ & 0.27 & 1.07 & $0.90-1.27$ & 1.23 & $0.98-1.55$ \\
\hline 2 & 1.11 & $0.91-1.35$ & 0.67 & 1.08 & $0.86-1.36$ & 1.06 & $0.72-1.56$ \\
\hline
\end{tabular}




\begin{tabular}{|c|c|c|c|c|c|c|c|}
\hline \multirow[b]{2}{*}{ Variable/Covariates } & \multicolumn{3}{|c|}{$\begin{array}{c}\text { Total } \\
(\mathrm{n}=\mathbf{3 , 9 0 8 )}\end{array}$} & \multicolumn{2}{|c|}{$\begin{array}{c}\text { Non-Hispanic White } \\
(n=2,574)\end{array}$} & \multicolumn{2}{|c|}{$\begin{array}{c}\text { Hispanic } \\
(n=1,334)\end{array}$} \\
\hline & OR & $95 \% \mathrm{Cl}$ & Pvalue & OR & $95 \% \mathrm{CI}$ & OR & $95 \% \mathrm{CI}$ \\
\hline \multicolumn{8}{|l|}{ IL6 (rs1800797) } \\
\hline 0 & Referent & 1.00 & & Referent & 1.00 & Referent & 1.00 \\
\hline 1 & 0.86 & $0.75-0.98$ & 0.30 & 0.81 & $0.69-0.97$ & 0.80 & $0.63-1.02$ \\
\hline 2 & 0.85 & $0.70-1.04$ & 0.38 & 0.72 & $0.58-0.91$ & 1.49 & $0.85-2.60$ \\
\hline \multicolumn{8}{|l|}{ IL6 ( rs1800796) } \\
\hline 0 & Referent & 1.00 & & Referent & 1.00 & Referent & 1.00 \\
\hline 1 & 1.02 & $0.87-1.20$ & 0.92 & 1.30 & $1.02-1.66$ & 0.90 & $0.72-1.14$ \\
\hline 2 & 1.02 & $0.69-1.50$ & 0.97 & 1.66 & $0.47-5.90$ & 1.00 & $0.66-1.53$ \\
\hline \multicolumn{8}{|l|}{ IL6 (rs1800795) } \\
\hline 0 & Referent & 1.00 & & Referent & 1.00 & Referent & 1.00 \\
\hline 1 & 0.83 & $0.73-0.95$ & 0.14 & 0.78 & $0.65-0.92$ & 0.82 & $0.64-1.03$ \\
\hline 2 & 0.86 & $0.70-1.04$ & 0.50 & 0.74 & $0.59-0.92$ & 1.27 & $0.74-2.16$ \\
\hline \multicolumn{8}{|l|}{ IL6( rs2069832) } \\
\hline 0 & Referent & 1.00 & & Referent & 1.00 & Referent & 1.00 \\
\hline 1 & 0.84 & $0.74-0.97$ & 0.23 & 0.79 & $0.66-0.94$ & 0.82 & $0.64-1.03$ \\
\hline 2 & 0.85 & $0.69-1.03$ & 0.37 & 0.72 & $0.58-0.91$ & 1.27 & $0.75-2.15$ \\
\hline \multicolumn{8}{|l|}{ IL6 (rs2069849) } \\
\hline 0 & Referent & 1.00 & & Referent & 1.00 & Referent & 1.00 \\
\hline 1 & 0.90 & $0.71-1.16$ & 0.50 & 1.04 & $0.71-1.51$ & 0.85 & 1.19 \\
\hline 2 & 0.37 & $0.04-3.55$ & 0.41 & 1.07 & $0.07-17.19$ & $<0.001$ & $>999.999$ \\
\hline
\end{tabular}

Definitions of SNP categories: "0"=homozygous wild type, "1"=heterozygote, "2"= homozygous variant Abbreviations: ADRB2- Adrenergic Receptor Beta-2, HAP-haplotype, ADRB3- Adrenergic Receptor Beta-3, AR- Androgen Receptor, ESR 1-Estrogen Receptor Alpha, IGF1- Insulin Growth Factor-1, IGFBP3- Insulin Growth Factor Binding Protein-3, IRS-1Insulin Receptor Substrate-1, IRS-2- Insulin Receptor Substrate-2, SHBG- Sex Hormone Binding Globulin, VDR- Vitamin D Receptor, IL6- Interleukin 6. 
Among the entire sample, none of the three ADRB2 haplotypes were associated with breast cancer risk; however the G-G haplotype did have a significant crude association among NHW women with 2 copies of the haplotype compared to zero copies, producing an $\mathrm{OR}=1.84,95 \% \mathrm{CI}: 1.18-2.84$ (Table 8 ). In contrast, Hispanic women did have a non-significant inverse association for the G-G haplotype, with an $O R=0.85,95 \%$ CI: 0.58-1.24 (Table 8). Because the significant association with NHW was observed, it was of interest to assess the G-G haplotype association with the dominant and recessive model of inheritance. The dominant model " 0 vs. $1+2$ " was not found to be significantly associated with breast cancer for the total sample or by ethnic group. The recessive model of " $0+1$ vs. 2 ", however, did yield a stronger crude association with breast cancer risk among NHW women $(\mathrm{OR}=1.92,95 \% \mathrm{CI}: 1.25-2.97)$ (Table 8$)$. The magnitude of the association did not significantly change for Hispanics. Modeling the G-G haplotype as a continuous variable did not provide significant results for this study and was not considered further for analyses. The following polymorphisms from Table 8 were identified and considered for interaction effects with the G-G haplotype due to their function and potential associations with risk of diabetes and/or obesity: IRS-1, IRS2, ADRB3, IGF-1, and IL6 variants.

Effect modification by ethnicity for the association with the G-G haplotype and risk of breast cancer was formally tested by using an interaction term in a multivariable logistic regression model consisting of the G-G haplotype, the ethnicity variable, and the interaction term between the G-G haplotype and ethnicity variable. The interaction between ethnicity and the G-G haplotype was statistically significant with a p value of 0.004 (Table 9). 
Table 9. Test of Interaction with Ethnicity using Model " $0+1$ vs. 2" G-G Haplotype for ADRB2

\begin{tabular}{lcll}
\hline Variable & Estimate & Standard Error & P- value \\
\hline G-G Haplotype & 0.119 & 0.072 & 0.100 \\
Ethnicity & -0.246 & 0.072 & 0.001 \\
G-G Hap X Ethnicity & -0.208 & 0.072 & 0.004 \\
\hline
\end{tabular}

An ethnic-specific haplotype variable was constructed to further examine the relationship between the G-G haplotype and breast cancer risk by ethnicity. The referent group consisted of NHW women with 0 copies of the G-G haplotype. Multivariable logistic regression models were evaluated using the ethnic-specific haplotype variable and the significant predictors from Table 7. Overall, none of the significant confounders from the univariable analysis significantly changed the point estimate; however, the final model was concluded based on the a priori knowledge of the relationship between the ADRB2 haplotype with breast cancer risk. After adjusting for center, BMI at referent year, menopausal status, history of diabetes, and genetic admixture, there was a positive association between the G-G haplotype with the recessive model and breast cancer risk among NHW women. Although the inverse association observed for Hispanic women was not statistically significant by itself, the heterogeneity test for difference between ethnic groups was significant $(\mathrm{p}=0.004)$ (Table 10).

Table 10. Interaction between Ethnicity and G-G Haplotype of ADRB2 SNPs Using Model " $0+1$ vs. 2 " $a$

\begin{tabular}{lccc}
\hline $\begin{array}{l}\text { Haplotype Levels of } \\
\text { G-G }\end{array}$ & $\begin{array}{c}\text { Non-Hispanic White } \\
(\mathrm{n}=2,574) \\
\text { OR }(95 \% \mathrm{CI})\end{array}$ & $\begin{array}{c}\text { Hispanic } \\
(\mathrm{n}=1,334) \\
\mathrm{OR}(95 \% \mathrm{CI})\end{array}$ & $\begin{array}{l}\text { O heterogeneity } \\
\end{array}$ \\
\hline $0+1$ (Referent) & 1.00 (Referent) & $0.87(0.71-1.08)$ & 0.004 \\
2 & $1.95(1.26-3.01)$ & $0.74(0.50-1.09)$ & \\
\hline${ }^{a}$ Odds ratios and 95\% Confidence Intervals adjusted for center, BMI at referent yr (one year prior to \\
date of diagnosis for cases and one year prior to selection for controls), menopausal status, history of \\
diabetes, and genetic admixture. \\
${ }^{b} P$ value for heterogeneity test difference between NHW and Hispanic women
\end{tabular}


Table 11. Test of Effect Modification by History of Diabetes with Ethnic-Specific ADRB2 G-G Haplotype.

\begin{tabular}{|c|c|c|c|c|}
\hline & \multicolumn{2}{|c|}{$\begin{array}{c}\text { Non-Hispanic White } \\
(\mathrm{n}=2,574)\end{array}$} & \multicolumn{2}{|c|}{$\begin{array}{l}\text { Hispanic } \\
(\mathrm{n}=1,334)\end{array}$} \\
\hline & OR & $95 \% \mathrm{CI}$ & OR & $95 \% \mathrm{CI}$ \\
\hline \multicolumn{5}{|l|}{ History of Diabetes } \\
\hline 0 copies of G-G Haplotype & Referent & 1.00 & 1.00 & $0.51-1.96$ \\
\hline 1 copy of G-G Haplotype & 1.17 & $0.66-2.06$ & 0.79 & $0.38-1.63$ \\
\hline 2 copies of G-G Haplotype & 4.91 & $0.52-46.60$ & 0.33 & $0.12-0.92$ \\
\hline \multicolumn{5}{|l|}{ No History of Diabetes } \\
\hline 0 copies of G-G Haplotype & Referent & 1.00 & 0.79 & $0.61-1.02$ \\
\hline 1 copy of G-G Haplotype & 0.85 & $0.71-1.02$ & 0.86 & $0.66-1.12$ \\
\hline 2 copies of G-G Haplotype & 1.77 & $1.13-2.77$ & 0.86 & $0.55-1.33$ \\
\hline
\end{tabular}

Odds ratios and $95 \%$ Confidence Intervals adjusted for center, BMI at referent yr (one year prior to date of diagnosis for cases and one year prior to selection for controls), menopausal status, and genetic admixture.

Effect modification by history of diabetes was tested with the association between the G-G haplotype and breast cancer. The divergence among ethnicities for the association with breast cancer risk was greater when modeled by history of diabetes. In fact, a significant inverse association was observed among Hispanics with 2 copies of the G-G haplotype $(\mathrm{OR}=0.33 ; 95 \%: 0.12-0.92)$ compared to NHW who yielded a nonsignificant positive association of $4.91,95 \% \mathrm{CI}: 0.52-46.60$ (Table 11 ). The multiplicative two-way interaction with history of diabetes was also significant when modeled as an interaction term with the $G-G$ haplotype $(p=0.025)$. The three-way multiplicative interaction term between the ethnic-specific haplotype and diabetes yielded a non-signification effect $(\mathrm{p}$ for interaction $=0.137)$. 
Table 12. Test of Effect Modification by Obesity with Ethnic-Specific ADRB2 G-G Haplotype

\begin{tabular}{|c|c|c|c|c|}
\hline & \multicolumn{2}{|c|}{$\begin{array}{c}\text { Non-Hispanic White } \\
(\mathrm{n}=2,574)\end{array}$} & \multicolumn{2}{|c|}{$\begin{array}{l}\text { Hispanic } \\
(\mathrm{n}=1,334)\end{array}$} \\
\hline & OR & $95 \% \mathrm{CI}$ & OR & $95 \% \mathrm{CI}$ \\
\hline \multicolumn{5}{|l|}{$\mathrm{BMI} \geq 30 \mathrm{~kg} / \mathrm{m}^{2}$} \\
\hline 0 copies of G-G Haplotype & Referent & 1.00 & 0.82 & $0.52-1.28$ \\
\hline 1 copy of G-G Haplotype & 1.06 & $0.75-1.49$ & 0.90 & $0.57-1.42$ \\
\hline 2 copies of G-G Haplotype & 3.01 & $1.22-7.44$ & 0.42 & $0.20-0.86$ \\
\hline \multicolumn{5}{|l|}{$\mathrm{BMI}<30 \mathrm{~kg} / \mathrm{m}^{2}$} \\
\hline 0 copies of G-G Haplotype & Referent & 1.00 & 0.82 & $0.62-1.09$ \\
\hline 1 copy of G-G Haplotype & 0.83 & $0.68-1.00$ & 0.83 & $0.61-1.11$ \\
\hline 2 copies of G-G Haplotype & 1.58 & $0.95-2.61$ & 0.95 & $0.59-1.54$ \\
\hline
\end{tabular}

Odds ratios and $95 \%$ Confidence Intervals adjusted for center, history of diabetes, menopausal status, and genetic admixture.

Effect modification by obesity status $\left(\mathrm{BMI} \geq 30 \mathrm{~kg} / \mathrm{m}^{2} v s . \mathrm{BMI}<30 \mathrm{~kg} / \mathrm{m}^{2}\right)$ was also examined with the association between the G-G haplotype and breast cancer. The divergence among ethnicities for the association with breast cancer risk was also enhanced when modeled by obesity and significant results were found for both ethnic groups. Among the obese group with 2 copies of the G-G haplotype, NHW women had an increased risk of breast cancer with an $\mathrm{OR}=3.01(95 \% \mathrm{CI}: 1.22-7.44)$ while Hispanics had a reduced risk with an $\mathrm{OR}=0.42(95 \% \mathrm{CI}: 0.20-0.86)$. Associations were not significant among women with BMI $<30 \mathrm{~kg} / \mathrm{m}^{2}$ (Table 12). Interestingly, the two-way multiplicative interaction effect between obesity and the G-G haplotype was not statistically significant $(p=0.200)$, neither was the three-way interaction with the ethnicspecific haplotype and obesity variable $(p=0.155)$. 
Table 13. Test of Effect Modification by Recent Hormone Exposure with EthnicSpecific ADRB2 G-G Haplotype

\begin{tabular}{|c|c|c|c|c|}
\hline & \multicolumn{2}{|c|}{$\begin{array}{c}\text { Non-Hispanic White } \\
(\mathrm{n}=2,574)\end{array}$} & \multicolumn{2}{|c|}{$\begin{array}{l}\text { Hispanic } \\
(n=1,334)\end{array}$} \\
\hline & OR & $95 \% \mathrm{CI}$ & OR & $95 \% \mathrm{CI}$ \\
\hline \multicolumn{5}{|l|}{ No Recent Hormone Exposure } \\
\hline 0 copies of G-G Haplotype & Referent & 1.00 & 1.08 & $0.65-1.79$ \\
\hline 1 copy of G-G Haplotype & 1.11 & $0.77-1.60$ & 1.10 & $0.66-1.83$ \\
\hline 2 copies of G-G Haplotype & 4.58 & $1.34-12.82$ & 0.58 & $0.24-1.40$ \\
\hline \multicolumn{5}{|l|}{ Recent Hormone Exposure } \\
\hline 0 copies of G-G Haplotype & Referent & 1.00 & 0.78 & $0.59-1.02$ \\
\hline 1 copy of G-G Haplotype & 0.83 & $0.68-1.00$ & 0.81 & $0.61-1.07$ \\
\hline 2 copies of G-G Haplotype & 1.47 & $0.90-2.41$ & 0.76 & $0.49-1.18$ \\
\hline
\end{tabular}

Odds ratios and 95\% Confidence Intervals adjusted for center, BMI at referent yr (one year prior to date of diagnosis for cases and one year prior to selection for controls), menopausal status, history of diabetes, and genetic admixture.

Results for effect modification by recent hormone exposure within the past 2 years were only significant among NHW women with no recent hormone exposure. Hispanic women with no recent hormone exposure did have a reduced risk of breast cancer with 2 copies of the G-G haplotype, however, the confidence interval was not significant and when compared to the recent hormone exposure group, point estimates for Hispanic women were not dramatically different. Among NHW, no recent hormone exposure did significantly increase the risk of breast cancer with women who had 2 copies of the G-G haplotype, but the confidence interval was wide, due to the fact that only a small subset of women were included among this risk group ( $n=22$ subjects) $(\mathrm{OR}=4.58 ; 95 \% \mathrm{CI}: 1.34-12.82)($ Table 13$)$

As hypothesized, it was of interest to investigate interaction effects between the ADRB2 G-G haplotype and family history of breast cancer ( $p$ for interaction $=0.686$ ), menopausal status ( $p$ for interaction $=0.438)$, aspirin use $(p$ for interaction $=0.983)$, and the identified insulin-related polymorphisms previously studied with the 4-CBCS (IRS-1, 
IRS-2, ADRB3, IGF-1, and IL6 variants). There were no significant interactions between the G-G haplotype and ethnicity with polymorphisms for IRS-1, IRS-2, ADRB3, IGF-1, and IL6 variants (Table 14). Adjusting for the specified SNPs of interests in the model did not significantly change the value of the point estimate for the ethnic-specific haplotype variable as well (data not shown).

Table 14. Statistical Interactions between ADRB2 G-G Haplotype by Ethnicity

\begin{tabular}{lcc}
\hline $\begin{array}{l}\text { Interaction Variable } \\
\text { with G-G Haplotype }\end{array}$ & $\begin{array}{c}\text { Non-Hispanic White } \\
P \text { for interaction }\end{array}$ & $\begin{array}{c}\text { Hispanic } \\
P \text { for interaction }\end{array}$ \\
\hline ADRB3 (Arg64Trp) & 0.968 & 0.725 \\
IRS-1 (G972R) & 0.541 & 0.989 \\
IRS-2 (G1057D) & 0.329 & 0.306 \\
IGF-1 (19CA repeats) & 0.964 & 0.827 \\
IL6 (rs1800797) & 0.588 & 0.358 \\
IL6 (rs1800796) & 0.961 & 0.780 \\
IL6 (rs1800795) & 0.492 & 0.118 \\
IL6 (rs2069832) & 0.265 & 0.239 \\
\hline
\end{tabular}

Abbreviations: ADRB3-Adrenergic Receptor Beta-3, IRS-1- Insulin Receptor Substrate1, IRS-2- Insulin Receptor Substrate-2, IGF-1- Insulin Growth Factor -1, IL6- Interleukin 6.

(IL6 rs2069849- validity of interaction with logistic regression models were questionable due to small numbers)

It was also of interest to evaluate the ADRB2 genetic association with estrogen receptor status. The distribution of the estrogen receptor status among the breast cancer cases is found in Table 15. More Hispanic cases had estrogen receptor negative (ER-) tumors compared to NHW cases, and the difference between ethnicities was statistically significant $(p=0.04)$. 
Table 15. Distribution of Estrogen Receptor (ER) Status for Breast Cancer Cases from the 4-Corners Breast Cancer Study

\begin{tabular}{|c|c|c|c|}
\hline & $\begin{array}{l}\text { Hispanics } \\
(\mathrm{n}=606)\end{array}$ & $\begin{array}{l}\text { Non-Hispanic } \\
\text { White }(n=1,244)\end{array}$ & $P$ value \\
\hline ER Status & $\mathrm{N} \quad(\%)$ & $N \quad(\%)$ & \\
\hline Positive & $285(47.0)$ & $638(51.3)$ & $0.04^{a}$ \\
\hline Negative & $99 \quad(16.3)$ & $164(13.2)$ & \\
\hline Unknown & $112(18.5)$ & $232 \quad(18.6)$ & $0.50^{b}$ \\
\hline
\end{tabular}

In order to test the outcome of estrogen receptor status, multinomial logistic regression models were used with the ethnic-specific G-G haplotype to compare risk groups. Point estimates were comparable and not significant among Hispanic women with 2 copies of the G-G haplotype for ER positive and ER negative tumors. However, NHW women with 2 copies of the G-G haplotype did have a slightly higher risk for ER negative tumors compared to $E R$ positive tumors, $(\mathrm{OR}=2.22 ; 95 \% \mathrm{CI}: 1.03-4.78$ and OR=1.71; 95\%:1.02-2.88 respectively) (Table 16$)$ 
Table 16. Multinomial Logistic Regression by Estrogen Receptor Status with Ethnic-Specific ADRB2 G-G Haplotype

\begin{tabular}{|c|c|c|c|c|}
\hline & \multicolumn{2}{|c|}{$\begin{array}{l}\text { Non-Hispanic White } \\
(\mathrm{n}=2,574)\end{array}$} & \multicolumn{2}{|c|}{$\begin{array}{l}\text { Hispanic } \\
(\mathrm{n}=1,334)\end{array}$} \\
\hline & OR & $95 \% \mathrm{CI}$ & OR & $95 \% \mathrm{Cl}$ \\
\hline \multicolumn{5}{|l|}{ Estrogen Receptor Positive } \\
\hline 0 copies of G-G Haplotype & Referent & 1.00 & 0.73 & $0.57-0.93$ \\
\hline 1 copy of G-G Haplotype & 0.82 & $0.67-1.01$ & 0.89 & $0.71-1.12$ \\
\hline 2 copies of G-G Haplotype & 1.71 & $1.02-2.88$ & 0.65 & $0.40-1.03$ \\
\hline \multicolumn{5}{|l|}{ Estrogen Receptor Negative } \\
\hline 0 copies of G-G Haplotype & Referent & 1.00 & 1.18 & $0.82-1.70$ \\
\hline 1 copy of G-G Haplotype & 0.90 & $0.63-1.28$ & 1.04 & $0.71-1.53$ \\
\hline 2 copies of G-G Haplotype & 2.22 & $1.03-4.78$ & 0.60 & $0.25-1.42$ \\
\hline
\end{tabular}

Odds ratios (ORs) and 95\% Confidence Intervals (95\% CI) adjusted for center, BMI at referent yr (one year prior to date of diagnosis for cases and one year prior to selection for controls), menopausal status, history of diabetes, and genetic admixture.

For this dissertation, it was also hypothesized to test the association of the ADRB2 polymorphisms and haplotypes with risk of obesity and diabetes. Unadjusted logistic regression models were constructed with the ethnic-specific G-G haplotype to investigate the association with both obesity at referent year, measured as $\mathrm{BMI} \geq 30$ $\mathrm{kg} / \mathrm{m}^{2}$ vs. BMI $<30 \mathrm{~kg} / \mathrm{m}^{2}$, and history of diabetes. Table 17 displays the results for the association of the G-G haplotype by ethnicity with risk of Type 2 diabetes and borderline disease. Hispanic women did have a positive association for Type 2 diabetes, regardless of the number of haplotype copies, suggesting that there is no association between the haplotype with diabetes. Results from Table 18 for the association with obesity by haplotype level and ethnicity look somewhat similar to results for history of Type 2 diabetes. It could be possible that the effect observed in these two tables by ethnicity is entirely due to ethnicity. This further suggests that there is something else associated with obesity and ethnicity and it could possibly be modifying the effect of the haplotype 
on breast cancer risk. No interaction effects existed between the haplotype and the other related SNPs (Table 14) which implies that it is not any of the other obesity/insulin related SNPs from the parent study. Therefore, this factor that is potentially associated with obesity, ethnicity, and breast cancer risk remains to be determined.

Table 17. Association between Ethnic-Specific G-G Haplotype of ADRB2 SNPs with Diabetes/Borderline Diabetic.

\begin{tabular}{lcc}
\hline Haplotype Levels of G-G & $\begin{array}{c}\text { Non-Hispanic White } \\
(\mathrm{n}=2,574) \\
\text { OR }(95 \% \mathrm{CI})\end{array}$ & $\begin{array}{c}\text { Hispanic } \\
(\mathrm{n}=1,334) \\
\text { OR }(95 \% \mathrm{CI})\end{array}$ \\
\hline 0 (referent) & 1.00 (Referent) & $1.97(1.52-2.57)$ \\
1 copy & $0.83(0.62-1.11)$ & $1.69(1.28-2.21)$ \\
2 copies & $0.52(0.21-1.30)$ & $2.56(1.66-3.96)$ \\
\hline
\end{tabular}

Unadjusted Odds ratios (ORs) and $95 \%$ Confidence Intervals $(95 \% \mathrm{CI})$.

Table 18. Association between Ethnic-Specific G-G Haplotype of ADRB2 SNPs with Obesity (BMI $\geq 30$ ).

\begin{tabular}{lcc}
\hline Haplotype Levels of G-G & $\begin{array}{c}\text { Non-Hispanic White } \\
(\mathrm{n}=2,574) \\
\text { OR }(95 \% \mathrm{CI})\end{array}$ & $\begin{array}{c}\text { Hispanic } \\
(\mathrm{n}=1,334) \\
\mathrm{OR}(95 \% \mathrm{CI})\end{array}$ \\
\hline 0 (referent) & 1.00 (Referent) & $1.59(1.30-1.94)$ \\
1 copy & $0.92(0.76-1.12)$ & $1.44(1.17-1.76)$ \\
2 copies & $1.05(0.65-1.70)$ & $1.84(1.28-2.65)$ \\
\hline Unadjusted Odds ratios (ORs) and $95 \%$ Confidence Intervals $(95 \% \mathrm{CI})$.
\end{tabular}




\section{DISCUSSION}

For this dissertation, the primary aim was to analyze the hypothesized association between the ADRB2 SNPs (rs1042713 (Arg16Gly); rs1042714 (Gln27Glu) and breast cancer risk, with particular concern on testing for effect modification by ethnicity. Within this sample of women, it was found that the candidate SNPs individually were not significantly associated with breast cancer risk, even after stratifying by ethnicity. Three haplotypes were identified between these two polymorphisms and were assessed with breast cancer risk as well, but a significant association was only observed for the G-G haplotype among non-Hispanic white women. Haplotypes for these two variants have proven to be worth researching.

The study of haplotypes renders certain concepts that should be discussed. Clark presented in his review that genetic variation within populations is organized into haplotypes, and using haplotypes versus the "one-SNP-at a time" approach for geneticassociation studies could improve analyses by reducing the dimension of association tests, which could in turn increase statistical power [56]. Association studies could be performed without taking into account that the SNPs are not independent of one another; however the linkage disequilibrium between the SNPs should be considered with the biological interpretation [56]. Clark emphasizes the importance of haplotypes, as they are biologically relevant with genetics. With each protein coding gene, an individual will have a polypeptide chain that corresponds with the maternal haplotype and one for the paternal haplotype. The biological importance of haplotypes results from the interactions 
that may occur between pairs or higher-order combinations of amino-acid sites [56]. The frequency of a haplotype encoding a new mutation may rise due to genetic drift. The haplotype could then become segmented due to recombination, and transmitted as a unit. Genetic variation then results not only from the recombination, but also from a combination of migration/population mixing, drift, selection, and mutation [56]. It is the genetic variation that is of interest when assessing any potential causal associations with disease risk.

Cagliani et al. [57] concluded that the structure of the ADRB2 haplotypes could warrant the need for association studies. It was also indicated that these association studies would benefit from identifying an ethnic-specific haplotype and this recommendation is based on the fact that their analysis revealed ethnic-specific differences among five human populations from the National Institute of Environmental Health Sciences (NIEHS) SNPs Program [57]. Cagliani et al. also notes that the complexity of the ADRB2 inferred haplotypes could be attributed to one of two situations: the gene has been subjected to balancing selection or it has been undergoing a selective sweep. In a report by Hernandez at al. [58], researchers identified the "classic selective sweep" model. This model occurs when the frequency increases for a new, strongly favorable mutation in a fixed population. The allele rises so swiftly in frequency there is little time for recombination and for it to uncouple itself from its genetic background. This process is further characterized by the allele sweeping out variation at linked sites, which in turn lowers the linked neutral diversity within the population and distorts the allele frequencies and linkage disequilibrium patterns [58]. 
The study by Cagliani et al. also documented ADRB2 genotype differences across population samples for genotypes with maximum and minimum relative fitness [57]. Theoretical models have shown that complex genotype distributions and differences among genotype frequencies could be caused by epistasis [59] and maternal selection [60], and Cagliani et al. believe both situations could potentially explain the ADRB2 genotype differences. Cagliani et al. also identified variation within the promoter region of the ADRB2 polymorphisms. For Europeans, all chromosomes carrying the Arg16 ('A' allele for rs 1042713) and Gln27 (' $\mathrm{C}$ ' allele for rs1042714) alleles display the same promoter structure; but in all other populations, the haplotypes' coding variants are split into two groups, and have different alleles in their promoter regions, suggesting different transcriptional activity [57]. This difference in transcriptional activity could possibly influence the ethnic differences observed among the G-G haplotype within this dissertation study.

In a report published prior to the review conducted by Cagliani and colleagues, Maxwell et al. investigated the ADRB2 haplotypes in eight distinct ethnic populations (Chinese, Southwest Asian, Saudi, Ghanaian, Kenyan, Sudanese, European, and Filipino). Haplotypes were shared among all ethnic groups, however, geographical variations were found in the frequency of the haplotype distributions. Maxwell et al. believe the ADRB2 haplotypes may have experienced a different mode of evolution for that locus compared to that of the human population gene-flow history [61]. It was also proposed that the differences among the frequencies between the observed clusters of populations resemble the historical haplotype groupings that have been found to have differences in functionality in regards to multiple disease related phenotypes [61]. 
As previously mentioned, the three ADRB2 haplotypes identified were, as follows: A-G (Arg16-Glu27), G-G (Gly16-Glu27), and G-C (Gly16-Gln27).

Interestingly, recent literature indicates for the common ADRB2 SNPs rs1042713 (Arg16Gly) and rs 1042714 (Gln27Glu), that linkage disequilibrium dictates that Glu27 homozygotes of rs 1042713 are nearly always homozygous for Gly16 of rs 1042714, and Arg 16 homozygotes of rs 1042713 are homozygous for Gln27 of rs1 042714 [17, 62-63]. The G-G haplotype which codes for Gly16-Glu27 was significantly associated with breast cancer in this dissertation study; and these results were only apparent in ethnicspecific analyses. Thus, ethnicity was found to be a significant effect modifier, yielding a statistically significant interaction effect with the $G-G$ haplotype $(p=0.004)$.

This is the first population-based case-control study to identify an association with an ADRB2 haplotype and breast cancer risk, although the effect differs between Hispanic and non-Hispanic white women. Two previous studies of individual ADRB2 SNPs reported either null [16] or inverse associations [15]; however, neither report investigated the association of ADRB2 haplotypes within the two most common ADRB2 variants and risk of breast cancer. Prior et al. [64] examined the relationship between ADRB2 haplotypes and glucose tolerance among a small sample of sedentary African American and non-Hispanic white women from Baltimore, Maryland. A specific aim of these researchers was to study the ADRB2 variants in the context of one haplotype, in an effort to address the inconsistencies from findings of previous studies that only looked at the individual genotypes for rs1042713 (Arg16Gly) and rs 1042714 (Gln27Glu) . Prior et al. concluded that ADRB2 haplotypes may mediate insulin action and possibly the risk of Type 2 diabetes in obese, postmenopausal women [64]. 
Unlike the previous studies with ADRB2 and breast cancer risk, this study was also able to test for interaction effects with Type 2 diabetes, given the relationship between the ADRB2 haplotypes with risk of Type 2 diabetes. As previously described, non-Hispanic white women with a history of diabetes and with 2 copies of the G-G haplotype had an increased risk of breast cancer, although the association was not statistically significant. In contrast, among Hispanic women, a statistically significant inverse association was observed. Results were not comparable for the non-diabetic group. One could infer diabetes is operating as an effect modifier in this breast cancer relationship, as it appears to enhance the divergent effect between Hispanic and nonHispanic whites.

The relationship between diabetes and breast cancer has been extensively studied, and findings have been inconsistent. Rollison et al. [65] investigated the association within the 4-CBCS in a previous publication. It was concluded that, overall, diabetes was not associated with breast cancer risk, even after stratification by ethnicity. In a systematic review of breast cancer associations with adiposity, Type 2 diabetes, and the metabolic syndrome, Vona-Davis et al. [66] identified ten epidemiological studies that reported diabetes to be a significant risk factor for breast cancer and two studies that did not find diabetes to a significant predictor. The report further evaluated several biological mechanisms by which the metabolic syndrome, central obesity, and Type 2 diabetes mutually promote the risk of breast cancer; however these mechanisms may occur differently among some populations. Vona-Davis and colleagues propose that the extraglandular oestrogen production and subsequent reduction in sex hormone-binding globulin increase the risk for hyperinsulinemia, resulting in increased plasma free 
oestradiol. This hormone driven cycle has mitogenic effects and triggers mitosis in breast epithelial cells. Increased leptin and decreased adiponectin production have also been implicated with breast cancer risk [66]. In a review on diabetes and breast cancer, Wolf et al. proposed three possible mechanisms responsible for the association between diabetes and breast cancer: activation of the insulin pathway, the regulation of endogenous sex hormones, and the activation of the insulin-like growth factor pathway [67]. In a later case-control study consisting of 79 diabetic and 158 age-matched nondiabetic patients, Wolf et al. reported that the relationship between diabetes and breast cancer remained even after adjustment for BMI [68].

The causal pathway between the ADRB2 G-G haplotype and breast cancer is difficult to explain. As previously discussed, the ADRB2 rs1042713 (Arg16Gly) and rs 1042714 (Gln27Glu) have been found to be associated with proven risk factors for breast cancer, i.e. diabetes and obesity. However, for this study diabetes appears to strengthen the interaction effect of the ADRB2 G-G haplotype and ethnicity. One would suspect obesity to play a similar role with this association. As previously reported, when tested as an interaction term in the logistic regression model with the G-G haplotype and obesity measured as BMI $\geq 30 \mathrm{~kg} / \mathrm{m}^{2}$, the interaction was not statistically significant ( $\mathrm{p}$ value $=0.200$ ). Yet, when the interaction between G-G haplotype and ethnicity was stratified by obesity status and adjusted for other important covariates, divergent results emerged. Among non-Hispanic white women with 2 copies of the G-G haplotype who were obese, the odds ratio was not only magnified but was also statistically significant. Conversely, a significant reduction for breast cancer risk was also observed for obese Hispanic women with 2 copies of the G-G haplotype. For women who are not obese, 
categorized by BMI $<30 \mathrm{~kg} / \mathrm{m}^{2}$, the results were not significant by ethnicity, and the divergence was weakened. Furthermore, when assessed as a single confounder and adjusted for in analyses, BMI was not found to be a significant covariate.

The biological relationship between ADRB2 and obesity has been widely studied, and results have been found to differ between the two common SNPs. The rs 1042714 SNP was found to be strongly associated with obesity in women [9]. Arner et al. [18] hypothesized that this particular ADRB2 variant is a potentially important gene polymorphism for obesity research as it could be considered a 'thrifty' gene as with the other adrenergic receptor genes [69]. Developed by James Neel, the "thrifty genotype" hypothesis described a hypothetical set of alleles that many diabetics are thought to carry in a small number of genes that would make them more effective with the intake and utilization of food. The theory was first thought to be related with Type 2 diabetes; however, since obesity often precedes diabetes, the theory could also be applied to obesity [70]. During times of "feast-or-famine" and when civilizations depended upon hunting and gathering, this genotype benefited humans [70]. However, among westernized society, this genotype is problematic, as it has been thought to increase the ability to store and reserve extra pounds, leading to obesity and risk of Type 2 diabetes.

In a more recent report, Eisenach et al. suggested that the ADRB2 rs1042714Gln27, also known as the ' $\mathrm{C}$ ' allele, may actually play an intermediate role in the development of obesity, as this specific allele has been linked with lower rate of lipolysis [17]. Lange et al. also found an association between rs1042714 and adipose tissue deposition [71]. Their findings have implications for risk of insulin resistance and diabetes. Visceral adipose tissue plays an important role in the development of these 
conditions. The vasculature of visceral adipose tissue allows free fatty acid flux into the liver, which leads to suppression of hepatic glucose production, hyperinsulinemia, and increased secretion of triglyceride particles [71]. The visceral cells have high lipolysis rates because of the elevated function of the beta-adrenergic receptors and decreased function of antilipolytic receptors. Visceral adipocytes also express lower levels of protective proteins against diabetes, i.e. adiponectin, leptin, and glycogen synthase [71].

The ADRB2 rs1042713 has also been implicated with risk of obesity as it has been found within adipose cells. Jocken et al. found that ADRB2 actually mediates lipolysis; they reported that obese women with homozygous Arg16 (homozygous A/A) genotypes had a marked increase in circulating free fatty acids and glycerol, and decreased fat oxidation [72]. From these results, it appears that the relationship between the two ADRB2 SNPs and obesity is not consistent between genotypes for each SNP. More research is needed to investigate any haplotype involvement between the ADRB2 gene and obesity. Within this study, the G-G haplotype did increase the risk of obesity; but interestingly, this positive association was only observed among Hispanics. Although the multiplicative interaction between obesity and the G-G haplotype was not significant for breast cancer, some evidence of effect modification was present. The complexity of the divergence between the point estimates by ethnicity still remains and is a chief theme of interest.

As noted earlier, ADRB2 haplotypes have been reported to be associated with insulin resistance and, more specifically, have been posited to mediate insulin action and the risk for Type 2 diabetes in obese women [64]. Results from this dissertation show the positive association between the G-G haplotype and risk of Type 2 diabetes was only 
significant among Hispanic women. The association between insulin and estrogen receptor status has been investigated for diabetes and breast cancer $[66,68,73]$, but not for the ADRB2 gene or haplotypes. In vitro insulin has a mitogenic effect, stimulating mitosis within ER-positive breast cancer cell lines. Insulin also increases aromatase activity, which also elevates mitogenic oestrogen levels [66]. Michel et al. concluded in the Nurses' Health Study that the relationship between Type 2 diabetes and breast cancer occurred mainly with ER-positive tumors [73]. In contrast, Wolf et al. [68] found breast cancer among diabetic patients was more strongly associated with estrogen receptor negative breast cancer. More research between diabetes and breast cancer ER status is warranted.

It was also of interest for this dissertation to evaluate the relationship between ADRB2 and estrogen receptor positive and negative breast cancer. This relationship was also attractive due to the established connection between ADRB2 and risk of Type 2 diabetes and because of the conflicting findings with the association between diabetes and ER status. Multinomial logistic regression was conducted to examine the association between the ADRB2 G-G haplotype and ethnicity by ER status. There were significant results for non-Hispanic white women with ER positive breast cancer; however the association was only marginally higher for ER negative tumors. Interestingly, for this population of women, more Hispanic women had ER negative tumors compared to nonHispanic white, yet non-significant inverse associations were present for both categories of ER status. Overall, these findings for this relationship did not indicate significant differences in breast cancer risk by estrogen receptor status. 
It was hypothesized that there would be significant interaction effects between the ADRB2 haplotype and the ADRB3 polymorphism, Trp64Arg, due to their functional relatedness in Type 2 diabetes and obesity research; however, a significant interaction was not indicated with these results. To date, there are no breast cancer epidemiological studies that have investigated interaction effects between ADRB2 haplotypes and the ADRB3, Trp64Arg. In fact, few publications have investigated the potential for interaction effects between the ADRB2 and ADRB3 polymorphisms with risk of obesity [74-76] and diabetes [77], and mixed results have been reported. Park and colleagues examined the interaction between ADRB2 and ADRB3 polymorphisms with adolescent obesity and observed a significant interaction effect between ADRB2 variant rs 1042714 and Trp64Arg on BMI $(\mathrm{p}<0.01)$ [75]. In the study conducted by Ellsworth et al., significant interactions on change in BMI were only found between polymorphisms for beta- 1 and beta-3 receptors among women from this cohort, and no significant effects were reported between $\mathrm{ADRB} 2$ and $\mathrm{ADRB} 3$ variants. It would be of interest for future genetic association studies to evaluate this potential interaction among other populations, not only for breast cancer risk, but also for obesity and diabetes research.

Previous publications for the 4-CBCS have documented marked ethnic differences in genetic associations with breast cancer risk [27, 31, 78]. Slattery et al. examined the relationship between IRS-1, IRS-2, and IGFBP3 and breast cancer risk with the 4-CBCS [27]. Ethnic differences were found between Hispanic and non-Hispanic white women who were not recently exposed to hormones and post-menopausal. Among post-menopausal Hispanic women not recently exposed to hormones, an increased risk of breast cancer was observed with the R allele of the G972R IRS1 polymorphism. This 
effect was not observed among non-Hispanic white women. Conversely, postmenopausal non-Hispanic white women not recently exposed to hormones showed an increased risk of breast cancer with the IGF-1 19 CA polymorphism; while there was no association in the Hispanic group. These findings further support the roles of the insulin and estrogen pathways in breast cancer risk, and also indicate how these metabolic pathways that potentially influence breast cancer may differ between ethnic groups [27]. In light of these findings with IRS-1 and IGF-1 polymorphisms, it was of interest to test if recent hormone exposure also modified the effect between ethnicity and the ADRB2 G-G haplotype. Interestingly, non-Hispanic white women with the highest level of the G-G haplotype, who had no recent hormone exposure within the past 2 years, were at significantly increased risk. For non-Hispanic white women who were exposed to HRT within the past 2 years and who had the highest level of the G-G haplotype, the risk was sharply attenuated and not significant. In contrast, recent hormone exposure did not significantly alter the risk estimates in Hispanic women, similar to results for the IGF-1 19 CA polymorphism [27].

In another report, Slattery et al. [31] investigated the association of the Xb1 polymorphism of estrogen receptor alpha (ESR1) and the CAG repeat of the androgen receptor (AR) genes with risk of breast cancer. Independently, the two polymorphisms did not have a significant association with breast cancer for Hispanic or non-Hispanic white women; however a statistically significant inverse association was observed for Hispanic women taking hormone therapy with the $\mathrm{X}$ allele $(\mathrm{OR}=0.61 ; 95 \% \mathrm{CI}$ : 0.39 0.94). In contrast, there was no statistically significant association among non-Hispanic 
white women. These findings further suggest that certain risk factors, such as effects of estrogen signaling, may differ for Hispanic and non-Hispanic White women [31].

It remains unclear why the ethnic differences between Hispanic and non-Hispanic white women occur in the realm of breast cancer research. Researchers attempt to adjust for potential confounding effects by including other covariates in analyses; however in the present research study adjusting for these covariates does not significantly affect the divergence in the associations. Lai et al. [79] posed a few intriguing concepts in an effort to explain the underlying circumstances behind these ethnic differences. Could subjects in the two ethnic groups be exposed to different environmental mutagens or to endogenous factors? Or could it be possible that the host reactions to breast cancer carcinogens differ between ethnicities? Or lastly, are there still unidentified oncogenes and/or tumor suppressor genes involved? [79].

Another intriguing concept within this dissertation study is how the ADRB2 G-G haplotype increased the risk of Type 2 diabetes and obesity in Hispanic women, but decreased the risk of breast cancer. Among non-Hispanic white women, the reverse effects were observed. It could be possible for the G-G haplotype that causes these amino-acid changes to cause a shift in the biochemistry of breast cancer carcinogenesis. Could the undetermined environmental mutagens posed by Lai et al. influence this shift? Or it could be the interaction of environmental factors with genetic background that is causing this divergence in association between these two ethnicities.

There are several strengths to this dissertation study. This study utilized population-based cases and controls to investigate the association between the two most common ADRB2 polymorphisms and their haplotypes and breast cancer risk. As 
previously mentioned, only two previous studies have examined the association between the ADRB2 gene and breast cancer risk: Huang et al. [15] investigated the association with only the rs1042714 (Gln27Glu) ADRB2 variant, while Feigelson et al. [16] utilized four ADRB2 tagging SNPs to assess the association with breast cancer. Neither of the studies included both of the common ADRB2 variants nor performed haplotype analyses. This is also the first study to report a significant positive association between an ADRB2 haplotype and breast cancer risk among non-Hispanic white women from a multicentered study in the United States.

There are common limitations with the genetic-association study design that should be addressed. The most common limitation among genetic-association studies can be attributed to the use of small sample sizes, which in turn affects the statistical power and produces high rates of false positive results [80-81]. This study is unique, as its sample size is substantial, allowing for sufficient power in testing of ethnic differences in breast cancer risk factors. Additional problems that persist with genetic-association studies are replication and validation [82]. These inconsistencies with replication of genetic-association results could be due to the false positive findings, false negative studies, or unevenness in association among different populations [83]. Replication of this study among similar populations with ample sample sizes would be of importance to assess the validity of our findings, however this may be difficult.

The robustness of the available covariates and other polymorphisms also allowed for testing of effect modification and for adjusting of common confounders; although sample size was more limited for testing effect modification with BMI, diabetes, and recent exposure to hormonal therapy. The case-control study design is susceptible to 
common limitations, such as recall and selection bias. One variable of interest for this dissertation was history of diabetes. This variable was based on self-report and not medical record review. Exposure information from medical records would not be subject to recall bias [84]. For this reason, misclassification is possible when testing the interaction effects of diabetes with the ADRB2 haplotype.

Although both ADRB2 genotypes and haplotypes were assessed in an effort to contribute to identifying other genetic risk factors within the etiology of breast cancer, knowledge is limited in terms of the functionality of the ADRB2 gene and its haplotypes in relation to the biological mechanisms associated with breast cancer risk. It could be argued that a better approach with this type of genetic-association study would be to genotype haplotype tagging SNPs, which could give a more descriptive and thorough assessment of the potential association between a gene and disease; however, there are limitations found with this approach. The reliability of the tagging SNPs with identifying a haplotype through resources such as HapMap, is not consistent among the genes. This issue is mainly caused by the selection of the tagging SNPs which is based on limited or fragmented linkage disequilibrium data [82]. Also, this type of genotyping may be an expensive endeavor in terms of genotyping costs and outside of the realm of this dissertation, depending upon the number of tagging SNPs identified.

A number of multiple comparisons were made for the statistical analyses but were warranted due to the background knowledge of the ADRB2 gene's relationship with diabetes, obesity, and presumed risk of breast cancer; and statistical analyses are consistent in the approach and methodology with previous studies of breast cancer risk in the 4-CBCS $[27,31,33,78]$. The most straightforward method for correcting p-values to 
minimize false positives from multiple hypothesis testing is by using the Bonferroni correction; however, in certain cases, this method fails to consider the correlation between genetic variants and related phenotypes [85]. Permutation testing does give an empirical method to correcting p-values from multiple testing so that the correlation in the actual data is retained [85]. Both of these methods for minimizing false positives from multiple comparisons could be explored using SAS [86] .

Other limitations presented with the 4-CBCS include low study response rates among Hispanic cases and controls, which could create a non-differential bias. In an effort to address these low response rates, a report for the 4-CBCS study described associations of age, ethnicity, and community characteristics with study nonparticipation for Hispanic and non-Hispanic white women [43]. It was concluded that older age was associated with a successful contact among Hispanic controls, but was negatively associated with interview cooperation. Using US Census data, it was also found that income, education, and urban/rural residence did not significantly affect participation by Hispanic cases or controls [43]. Also $25 \%$ of the participants in the study did not provide a blood specimen; however, the rates of those who did give blood were similar among the two ethnic groups- $76.6 \%$ of cases and $82.4 \%$ of controls [41].

Unfortunately with all genetic studies, there is the possibility for genotyping error. Stochastic errors may occur and can be defined by two terms-allelic dropout and false alleles. Allelic dropout occurs when an allele of the heterozygote erratically fails to PCR amplify. False alleles occur when the true allele is misgenotyped due to PCR/electrophoresis artifacts or just by human error in reading or the recording of data [87]. Genotyping errors can introduce bias and result in false-positive findings [85]. In an 
effort to prevent such bias, both of these situations were addressed, as drop outs were reanalyzed and all genotypes were "called" or scored by two individuals with any discrepancies being scored by a third reader.

This dissertation is just one of few studies that examined the potential association between the ADRB2 gene and breast cancer risk. Given the associations with both Type 2 diabetes and obesity, it is likely that both somehow play a role with the ADRB2 relationship and risk of breast cancer. It is important for future population-based studies to investigate this relationship among other ethnic groups, due to the previously discussed characteristics of this specific gene's polymorphisms and haplotypes. Ideally, multicenter collaborations with much larger sample sizes would be the next step to improving genetic-association studies such as this study; however the cost of such studies would be highly expensive. These investigations would be of importance as they could account for biological disparities in breast cancer incidence. There are also other implications for future biological research to gain more knowledge about the biological mechanism that contributes to this possible association with breast cancer and possible ethnic differences. 


\section{REFERENCES}

1. Litonjua, A.A., et al., Very important pharmacogene summary ADRB2.

Pharmacogenet Genomics, 2010. 20(1): p. 64-9.

2. NCBI dbSNP Short Genetic Variations. 2010 [cited 2011 07/15/2011]; Available from: http:/www.ncbi.nlm.nih.gov/projects/SNP/snp_ref.cgi?rs=1042713.

3. Gjesing, A.P., et al., Studies of the associations between functional beta2adrenergic receptor variants and obesity, hypertension and type 2 diabetes in 7,808 white subjects. Diabetologia, 2007. 50(3): p. 563-8.

4. Chang, T.J., et al., The Argl6Gly polymorphism of human beta2-adrenoreceptor is associated with type 2 diabetes in Taiwanese people. Clin Endocrinol (Oxf), 2002. 57(5): p. 685-90.

5. Ishiyama-Shigemoto, S., et al., Association of polymorphisms in the beta2adrenergic receptor gene with obesity, hypertriglyceridaemia, and diabetes mellitus. Diabetologia, 1999. 42(1): p. 98-101.

6. Jalba, M.S., G.G. Rhoads, and K. Demissie, Association of codon 16 and codon 27 beta 2-adrenergic receptor gene polymorphisms with obesity: a meta-analysis. Obesity (Silver Spring), 2008. 16(9): p. 2096-106.

7. Pereira, A.C., et al., Beta2 adrenoceptor functional gene variants, obesity, and blood pressure level interactions in the general population. Hypertension, 2003. 42(4): p. 685-92.

8. Lange, L.A., et al., Association of adipose tissue deposition and beta-2 adrenergic receptor variants: the IRAS family study. Int J Obes (Lond), 2005. 29(5): p. 44957.

9. Large, V., et al., Human beta-2 adrenoceptor gene polymorphisms are highly frequent in obesity and associate with altered adipocyte beta-2 adrenoceptor function. J Clin Invest, 1997. 100(12): p. 3005-13. 
10. Cakir, Y., et al., Beta-adrenergic and arachidonic acid-mediated growth regulation of human breast cancer cell lines. International journal of oncology, 2002. 21(1): p. 153-7.

11. Hong, S.H., et al., Relationship of arachidonic acid metabolizing enzyme expression in epithelial cancer cell lines to the growth effect of selective biochemical inhibitors. Cancer research, 1999. 59(9): p. 2223-8.

12. Plummer, H.K., 3rd, et al., Expression of inwardly rectifying potassium channels (GIRKs) and beta-adrenergic regulation of breast cancer cell lines. BMC cancer, 2004. 4: p. 93.

13. Vandewalle, B., F. Revillion, and J. Lefebvre, Functional beta-adrenergic receptors in breast cancer cells. Journal of cancer research and clinical oncology, 1990. 116(3): p. 303-6.

14. Draoui, A., et al., Beta-adrenergic receptors in human breast cancer: identification, characterization and correlation with progesterone and estradiol receptors. Anticancer research, 1991. 11(2): p. 677-80.

15. Huang, X.E., et al., Possible association of beta2-and beta3-adrenergic receptor gene polymorphisms with susceptibility to breast cancer. Breast Cancer Res, 2001. 3(4): p. 264-9.

16. Feigelson, H.S., et al., Genetic variation in candidate obesity genes ADRB2, ADRB3, GHRL, HSDIIB1, IRS1, IRS2, and SHC1 and risk for breast cancer in the Cancer Prevention Study II. Breast Cancer Res, 2008. 10(4): p. R57.

17. Eisenach, J.H. and E.D. Wittwer, \{beta $\}$-Adrenoceptor gene variation and intermediate physiological traits: prediction of distant phenotype. Experimental physiology, 2010. 95(7): p. 757-64.

18. Arner, P. and J. Hoffstedt, Adrenoceptor genes in human obesity. Journal of internal medicine, 1999. 245(6): p. 667-72.

19. Kurokawa, N., et al., The ADRB3 Trp64Arg variant and BMI: a meta-analysis of 44833 individuals. International journal of obesity, 2008. 32(8): p. 1240-9. 
20. McKean-Cowdin, R., et al., The ADRB3 Trp64Arg variant and obesity in AfricanAmerican breast cancer cases. International journal of obesity, 2007. 31(7): p. $1110-8$.

21. Gjesing, A.P., et al., Association of the beta3-adrenergic receptor Trp64Arg polymorphism with common metabolic traits: studies of 7605 middle-aged white people. Molecular genetics and metabolism, 2008. 94(1): p. 90-7.

22. Dunajska, K., et al., beta(3)-adrenergic receptor polymorphism and metabolic syndrome in postmenopausal women. Gynecological endocrinology : the official journal of the International Society of Gynecological Endocrinology, 2008. 24(3): p. 133-8.

23. Zhu, L.Y., L.Y. Hu, and X.L. Li, [A prospective study of the relationship between Trp64Arg beta(3)-adrenergic receptor gene polymorphism and metabolic syndrome]. Zhonghua nei ke za zhi [Chinese journal of internal medicine], 2008. 47(10): p. 811-4.

24. Dearth, R.K., et al., Mammary tumorigenesis and metastasis caused by overexpression of insulin receptor substrate I (IRS-1) or IRS-2. Mol Cell Biol, 2006. 26(24): p. 9302-14.

25. Lee, A.V., et al., Enhancement of insulin-like growth factor signaling in human breast cancer: estrogen regulation of insulin receptor substrate-1 expression in vitro and in vivo. Mol Endocrinol, 1999. 13(5): p. 787-96.

26. Bommer, G.T., et al., IRSI regulation by Wnt/beta-catenin signaling and varied contribution of IRS1 to the neoplastic phenotype. J Biol Chem, 2010. 285(3): p. 1928-38.

27. Slattery, M.L., et al., Genetic variation in IGF1, IGFBP3, IRS1, IRS2 and risk of breast cancer in women living in Southwestern United States. Breast Cancer Res Treat, 2007. 104(2): p. 197-209.

28. Slattery, M.L., et al., Aspirin, NSAIDs, and colorectal cancer: possible involvement in an insulin-related pathway. Cancer Epidemiol Biomarkers Prev, 2004. 13(4): p. 538-45.

29. Rosen, C.K.E., Vereault D., Adler RA, Rackoff PJ, Craig WY, Witte S, RogersJ, Bilezikian JP. , Association between serum insulin growth factor-I (IGF-I) and a 
simple sequence repeat in IGF-I gene: implications for genetic studies of bone mineral density. . J Clin Endocrinol Metab 1998. 83 (7): p. 2286-2290.

30. Lautier, C., et al., Complex haplotypes of IRS2 gene are associated with severe obesity and reveal heterogeneity in the effect of Glyl057Asp mutation. Hum Genet, 2003. 113(1): p. 34-43.

31. Slattery, M.L., et al., ESRI, AR, body size, and breast cancer risk in Hispanic and non-Hispanic white women living in the Southwestern United States. Breast Cancer Res Treat, 2007. 105(3): p. 327-35.

32. Sweeney, C.W., R.K., Byers, T., Baumgartner, K.B., Giuliano, A.R., Herrick, J.S., Murtaugh, M.A., Samowitz, W.S., Slattery, M.K., Genetic Admixture among Hispanics and Candidate Gene Polymorphisms: Potential for Confounding in a Breast Cancer Study. Cancer Epidemiol Biomarkers Prev, 2007. 16(1): p. 142150.

33. Slattery, M.L., et al., Modifying effects of IL-6 polymorphisms on body sizeassociated breast cancer risk. Obesity (Silver Spring), 2008. 16(2): p. 339-47.

34. Brinton L, L.J., Devesa SS., Cancer of the Breast 5th ed. Epidemiology of Breast Cancer, ed. S.J. Donegan WL. 2002, Philadelphia: Saunders.

35. Ursin, G., et al., A meta-analysis of body mass index and risk of premenopausal breast cancer. Epidemiology, 1995. 6(2): p. 137-41.

36. Smith, D.E., et al., Longitudinal changes in adiposity associated with pregnancy. The CARDIA Study. Coronary Artery Risk Development in Young Adults Study. JAMA : the journal of the American Medical Association, 1994. 271(22): p. $1747-51$.

37. Bergstrom A, P.P., Tenet V, Wolk A, Adami HO, Overweight as an avoidable cause of cancer in Europe. Int J Cancer, 2001. 91: p. 421-430.

38. Rinaldi S, K.T., Peeters PHM, Lahmann PH Anthropometric measures, endogenous sex steroids and breast cancer risk in postmenopausal women: $A$ study within the EPIC cohort. Int J Cancer, 2006. 118: p. 2832-2839. 
39. Morimoto, L.M., et al., Obesity, body size, and risk of postmenopausal breast cancer: the Women's Health Initiative (United States). Cancer Causes Control, 2002. 13(8): p. 741-51.

40. Wenten, M., et al., Associations of weight, weight change, and body mass with breast cancer risk in Hispanic and non-Hispanic white women. Ann Epidemiol, 2002. 12(6): p. 435-4.

41. Slattery, M.L., et al., Body size, weight change, fat distribution and breast cancer risk in Hispanic and non-Hispanic white women. Breast Cancer Res Treat, 2007. 102(1): p. 85-101.

42. Howard, C.A., et al., Survey research in New Mexico Hispanics: some methodological issues. American journal of epidemiology, 1983. 117(1): p. 27-34.

43. Sweeney, C., et al., Recruiting Hispanic women for a population-based study: validity of surname search and characteristics of nonparticipants. American journal of epidemiology, 2007. 166(10): p. 1210-9.

44. Irwin, M.L., et al., Moderate-intensity physical activity and fasting insulin levels in women: the Cross-Cultural Activity Participation Study. Diabetes care, 2000. 23(4): p. 449-54.

45. Ainsworth, B.E., et al., Compendium of physical activities: an update of activity codes and MET intensities. Med Sci Sports Exerc, 2000. 32(9 Suppl): p. S498504.

46. Falush, D., M. Stephens, and J.K. Pritchard, Inference of population structure using multilocus genotype data: linked loci and correlated allele frequencies. Genetics, 2003. 164(4): p. 1567-87.

47. Pritchard, J.K., M. Stephens, and P. Donnelly, Inference of population structure using multilocus genotype data. Genetics, 2000. 155(2): p. 945-59.

48. Slattery, M.L., et al., Physical activity and breast cancer risk among women in the southwestern United States. Ann Epidemiol, 2007. 17(5): p. 342-53.

49. Fejerman, L., et al., Genetic ancestry and risk of breast cancer among U.S. Latinas. Cancer research, 2008. 68(23): p. 9723-8. 
50. Zaykin, D.V., et al., Testing association of statistically inferred haplotypes with discrete and continuous traits in samples of unrelated individuals. Hum Hered, 2002. 53(2): p. 79-91.

51. Shein-Chung Chow, J.S., Hansheng Wang, Large Sample Tests for Proportions, in Sample Size Calculations in Clinical Research, 2nd Edition, C.H.C.B. Series, Editor. 2008, Marcel Dekker, Inc: New York. p. 88-94.

52. The International HapMap Project 2010 [cited 2010 06/11/2010]; Available from: http://hapmap.ncbi.nlm.nih.gov/.

53. Altekruse SF, K.C., Krapcho M, Neyman N, Aminou R, Waldron W, Ruhl J, Howlader N, Tatalovich Z, Cho H, Mariotto A, Eisner MP, Lewis DR, Cronin K, Chen HS, Feuer EJ, Stinchcomb DG, Edwards BK SEER Cancer Statistics Review, 1975-2007. 2009, National Cancer Institute: Bethesda, MD.

54. Sahai, H. and A. Khurshid, Formulae and tables for the determination of sample sizes and power in clinical trials for testing differences in proportions for the twosample design: a review. Statistics in medicine, 1996. 15(1): p. 1-21.

55. Dobson, A.J.G., Val J., Sample sizes for comparing two independent proportions using the continuity-corrected arc sine transformation The Statistician, 1986. 35: p. 3 .

56. Clark, A.G., The role of haplotypes in candidate gene studies. Genetic epidemiology, 2004. 27(4): p. 321-33.

57. Cagliani, R., et al., Diverse evolutionary histories for beta-adrenoreceptor genes in humans. American journal of human genetics, 2009. 85(1): p. 64-75.

58. Hernandez, R.D., et al., Classic Selective Sweeps Were Rare in Recent Human Evolution. Science, 2011. 331(6019): p. 920-924.

59. Hastings, A., Stable cycling in discrete-time genetic models. Proc Natl Acad Sci U S A, 1981. 78(11): p. 7224-5.

60. Gavrilets, S., One-locus two-allele models with maternal (parental) selection. Genetics, 1998. 149(2): p. 1147-52. 
61. Maxwell, T.J., et al., Beta-2 adrenergic receptor genotypes and haplotypes in different ethnic groups. Int J Mol Med, 2005. 16(4): p. 573-80.

62. Hawkins, G.A., et al., Sequence, haplotype, and association analysis of ADRbeta2 in a multiethnic asthma case-control study. American journal of respiratory and critical care medicine, 2006. 174(10): p. 1101-9.

63. Drysdale, C.M., et al., Complex promoter and coding region beta 2-adrenergic receptor haplotypes alter receptor expression and predict in vivo responsiveness. Proceedings of the National Academy of Sciences of the United States of America, 2000. 97(19): p. 10483-8.

64. Prior, S.J., A.P. Goldberg, and A.S. Ryan, ADRB2 haplotype is associated with glucose tolerance and insulin sensitivity in obese postmenopausal women. Obesity, 2011. 19(2): p. 396-401.

65. Rollison, D.E., et al., Population-based case-control study of diabetes and breast cancer risk in Hispanic and non-Hispanic White women living in US southwestern states. Am J Epidemiol, 2008. 167(4): p. 447-56.

66. Vona-Davis, L., M. Howard-McNatt, and D.P. Rose, Adiposity, type 2 diabetes and the metabolic syndrome in breast cancer. Obes Rev, 2007. 8(5): p. 395-408.

67. Wolf, I., et al., Diabetes mellitus and breast cancer. The lancet oncology, 2005. 6(2): p. 103-11.

68. Wolf, I, et al., Association between diabetes mellitus and adverse characteristics of breast cancer at presentation. European journal of cancer, 2006. 42(8): p. 1077-82.

69. Swinburn, B.A., The thrifty genotype hypothesis: how does it look after 30 years? Diabetic medicine : a journal of the British Diabetic Association, 1996. 13(8): p. 695-9.

70. Neel, J.V., Diabetes mellitus: a "thrifty" genotype rendered detrimental by "progress"? 1962. Bulletin of the World Health Organization, 1999. 77(8): p. 694-703; discussion 692-3. 
71. Lange, L.A., et al., Association of adipose tissue deposition and beta-2 adrenergic receptor variants: the IRAS family study. International journal of obesity, 2005. 29(5): p. 449-57.

72. Jocken, J.W., et al., Association of a beta-2 adrenoceptor (ADRB2) gene variant with a blunted in vivo lipolysis and fat oxidation. International journal of obesity, 2007. 31(5): p. 813-9.

73. Michels, K.B., et al., Type 2 diabetes and subsequent incidence of breast cancer in the Nurses' Health Study. Diabetes care, 2003. 26(6): p. 1752-8.

74. Ukkola, O., et al., Interactions among the alpha2-, beta2-, and beta3-adrenergic receptor genes and obesity-related phenotypes in the Quebec Family Study. Metabolism: clinical and experimental, 2000. 49(8): p. 1063-70.

75. Park, H.S., Y. Kim, and C. Lee, Single nucleotide variants in the beta2adrenergic and beta3-adrenergic receptor genes explained $18.3 \%$ of adolescent obesity variation. Journal of human genetics, 2005. 50(7): p. 365-9.

76. Ellsworth, D.L., et al., Interactive effects between polymorphisms in the betaadrenergic receptors and longitudinal changes in obesity. Obesity research, 2005. 13(3): p. 519-26.

77. Kilpelainen, T.O., et al., Interaction of single nucleotide polymorphisms in ADRB2, ADRB3, TNF, IL6, IGF1R, LIPC, LEPR, and GHRL with physical activity on the risk of type 2 diabetes mellitus and changes in characteristics of the metabolic syndrome: The Finnish Diabetes Prevention Study. Metabolism: clinical and experimental, 2008. 57(3): p. 428-36.

78. Slattery, M.L., et al., Replication of five GWAS-identified loci and breast cancer risk among Hispanic and non-Hispanic white women living in the Southwestern United States. Breast cancer research and treatment, 2011.

79. Lai, H., et al., Prevalence and spectrum of 53 mutations in white Hispanic and non-Hispanic women with breast cancer. Breast cancer research and treatment, 2003. 81(1): p. 53-60.

80. Pharoah, P.D., et al., Association studies for finding cancer-susceptibility genetic variants. Nat Rev Cancer, 2004. 4(11): p. 850-60. 
81. Ioannidis, J.P., T.A. Trikalinos, and M.J. Khoury, Implications of small effect sizes of individual genetic variants on the design and interpretation of genetic association studies of complex diseases. Am J Epidemiol, 2006. 164(7): p. 60914.

82. Jorgensen, T.J., et al., Hypothesis-driven candidate gene association studies: practical design and analytical considerations. Am J Epidemiol, 2009. 170(8): p. 986-93.

83. Lohmueller, K.E., et al., Meta-analysis of genetic association studies supports a contribution of common variants to susceptibility to common disease. Nat Genet, 2003. 33(2): p. 177-82.

84. Rothman, K.J.G., Sander, Case-Control Studies, in Modern Epidemiology, 2nd Edition. 1998, Lippincott Williams \& Wilkins: Philadelphia. p. 93-114.

85. Newton-Cheh, C. and J.N. Hirschhorn, Genetic association studies of complex traits: design and analysis issues. Mutat Res, 2005. 573(1-2): p. 54-69.

86. Westfall, P.H., Randall, T.D., Rom, D., Wolfinger, R.D., Hochberg, Y., Multiple Comparisons and Multiple Tests Using SAS. 1999, Cary, N.C. USA: SAS Institute Inc.

87. Broquet, T. and E. Petit, Quantifying genotyping errors in noninvasive population genetics. Mol Ecol, 2004. 13(11): p. 3601-8. 
APPENDIX

Letters for IRB Approval 
UNNIEERSIIY Oำ

It's Happening Here.
Human Subjects Protection Program Office

MedCenter One - Suite 200

501 E. Broadway

Louisville, KY 40202-1798

Office: 502.852 .5188 Fax: 502.852 .2164

March 13, 2008

Kathy Baumgartner, Ph.D.

Epidemiology \& Population Health

K Building, Room 4056

555 South Floyd Street

Louisville, Kentucky 40202

\section{RE: $\quad 238.05$ - 4-Corners Women's Health Study}

Dear Doctor Baumgartner:

The following items have been received by the Human Subjects Protection Program Office and approved by the chair of the Institutional Review Board (IRB) through the expedited review procedure according to 45 CFR $46.110(B)$ :

- Amendment \#11, dated 3/11/2008

The modifications include:

- The addition of the following personnel to the study: Avonne Connor, MPH and Stephanie Denkhoff, BS.

- The removal of Laura Herman from the study.

The committee will be advised of this action at their next full board meeting. Please send all inquires and electronic revised/requested items to our office email address at hsppofc@louisville.edu.

Sincerely,

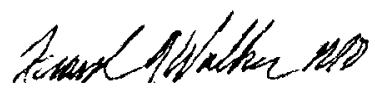

Frank A. Walker, M.D., Vice Chair,

Biomedical Institutional Review Board

FAW/elp 


\section{unvensistr of LOUISVILLE \\ It's Happening Here.}

Human Subjects Protection Frogran Ofice

Meocenter One - Sutte 200

$501 \mathrm{E}$ sroadway

Louiswille $k \backslash 40202-1798$

ofice: 502.852385 Fax: 5025522184

January 18,2011

Kathy Eaunganner, Fr.D.

Epidemology \& Population Health

485 East Gray $5 t, 5$ e 230

Luisvile. Kentunky 40202

RE: IRB: 238.05 - 4-Corners Women's Health Study

Dear Dr. Bumgartner.

The folowng items have been regeived by the Human Subjects Frotection Frogram Onice and approved by the chair of the institutional Revew Boand IRB through the expedited review procedure scoording to 45 CFR 4e. 1 OCE

- Amendment $\$ 20$, dated 1122011

- Health Disparities Proposal, not dated

- Cissetation Froposal, not dated

The modfastons include:

- Latoratory analys is will be performed on spesimens obtaned during this study

This action will be repored prompty to the RB at a scheduled full Board meting. Fiease send al inquires and electronic rexisedrequested tens to our ofice enal aderess at

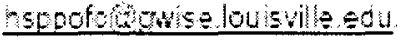

Gincerey.

Depe a patiog

Serge A. Marinez, W.D. J.O., Vice Chair

Eiomedical Instutional Revew Board

SAMEF 


\title{
CURRICULUM VITAE \\ Avonne E. Connor
}

\author{
418 Lyndon Lane \\ Louisville, KY 40222 \\ 502-802-7862 \\ aconn39@gmail.com
}

\section{EDUCATION}

Doctor of Philosophy, Epidemiology and Population Health

University of Louisville, KY

Specialization: Breast Cancer Research

Dissertation: "Adrenergic Receptor Beta-2 Candidate SNPs and Breast Cancer Risk among a Diverse Sample of Women from the 4-Corners Breast Cancer Study."

Anticipated Graduation: August, 2011

\section{Master of Public Health}

University of Louisville, KY

Specialization: Epidemiology

Practicum: "Primary Care Research Readiness-the Outpatient Clinic as Laboratory-Part

II: Drug Metabolizing Variance."

(Dr. Kathy B. Baumgartner, Academic Advisor; Dr. Toni P. Miles, Preceptor)

Graduation Date: May, 2007

\section{Bachelor of Arts Biology, Magna Cum Laude}

University of Louisville, Louisville, KY

Specialization: Pre-Medicine

Graduation Date: May, 2005

\section{GRANTS, HONORS AND AWARDS}

Susan B. Komen, Dissertation Training Grant Recipient, 2009-present Graduate Research Assistantship, 2010 - present, University of Louisville Graduate Research Assistantship, 2008 - 2009, University of Louisville Graduate Research Assistantship, 2007 - 2008, University of Louisville Minority Academic Fellowship, 2006 - 2007, University of Louisville Woodford R. Porter Achiever Academic Scholarship, 2001 - 2005, University of Louisville 
Humana Foundation Scholarship, 2001-2005

National Urban League Scholarship, 2001-2005

Phi Kappa Phi Honor Fraternity, 2007, University of Louisville

Golden Key Club Member, 2003, University of Louisville

Alpha Epsilon Delta Biology Honors Fraternity 2003, University of Louisville

\section{ASSOCIATION MEMBERSHIPS}

Society of Epidemiological Research (SER), 2009 - present

\section{WORK EXPERIENCE}

\section{University of Louisville, KY}

Graduate Research Assistant, Long-Term Quality of Life Phase of the New Mexico Women's Health Study. Department of Epidemiology and Population Health, 2007- Present.

- Involvement with the design and development of materials useful to study through the use of databases such as Oracle, Access, SAS, and graphics software.

- Identify resources, collect data, and develop protocols and data dictionaries.

- Enter and analyze data, and prepares summaries and reports of findings.

- Work with program faculty and staff to monitor progress on the established project goals and objectives.

\section{Humana Inc, Louisville, KY}

Project Analyst, Department of Center for Consumer Messaging, Humana Inc. 2005- 2006.

- Manages e-Health initiatives on the Humana member web portal to facilitate health education to members and assists with Medicare member transfers.

\section{SERVICE}

University-

Health Career Expo- Moore Traditional School, Louisville, KY 
Presenter- representative for University of Louisville, School of Public Health and Information Sciences. November $18^{\text {th }}, 2010$.

Health Career Expo- Olmstead Middle School for Girls, Louisville, KY

Presenter- representative for University of Louisville, School of Public Health and Information Sciences. March 30, 2011.

Community-

American Cancer Society-Making Strides against Breast Cancer Walk

Participant- team walker and fundraiser. October 2009, October 2010.

\section{PRESENTATIONS}

Connor, A., Baumgartner, R.N., Yang, D., Slattery, M.L. Giuliano, A.R., Byers, T., Baumgartner, K.B. (April 1, 2011). Differences between Hispanic and non-Hispanic White Women with Breast Cancer for Clinical Characteristics and their Correlates. Abstract/Poster presented at the Third Annual Graduate Research Symposium, University of Louisville, KY.

Connor, A., Baumgartner, R.N., Yang, D., Slattery, M.L. Giuliano, A.R., Byers, T., Baumgartner, K.B. (September 13, 2010). Differences between Hispanic and nonHispanic White Women with Breast Cancer for Clinical Characteristics and their Correlates. Abstract/Poster presented at the American College of Epidemiology Annual Conference, San Francisco, CA.

Connor, A., Baumgartner, R.N., Yang, D., Slattery, M.L. Giuliano, A.R., Byers, T., Baumgartner, K.B. (October 29, 2008). A comparison of Hispanic vs. non-Hispanic White Breast Cancer Cases for the Association of Body Mass Index and Waist Circumference with Estrogen Receptor Status. Abstract/Poster presented at Seventh Annual All Brown Cancer Center Retreat, Louisville, KY.

\section{MANUSCRIPTS IN PREPARATION}

Connor, A., Baumgartner, R.N., Yang, D., Slattery, M.L. Giuliano, A.R., Byers, T., Baumgartner, K.B. Differences between Hispanic and non-Hispanic White Women with Breast Cancer for Clinical Characteristics and their Correlates.

Connor, A., Yang, D., Pinkston, C., Baumgartner, R.N., Baumgartner, K.B. Obesity measured by body mass index and risk of breast cancer mortality in Hispanic and non-Hispanic white women from New Mexico.

\section{PUBLICATIONS}

Miles, T., Hanson, S., Kidd, L., Connor, A., Jortani, S. Sensitivity Analysis of SelfIdentified Race and Ethnicity (SIRE): Screening for Single Nucleotide Polymorphisms. 
Public access. (Nature Precedings: hdl:10101/npre.2008.1524.1 : Posted 17 Jan 2008)

\section{RESEARCH INTERESTS}

Special populations (minorities)

Genetics/Single Nucleotide Polymorphisms (SNPs) and breast cancer risk

Associations between anthropometrics with breast cancer risk, prognosis, and survival and differences by ethnicity

Effects of physical activity and quality of life with breast cancer survivors

Adherence to recommended screening practices for breast cancer

Biological pathways and the obesity/breast cancer relationship

Effects of modifiable risk factors and breast cancer risk 